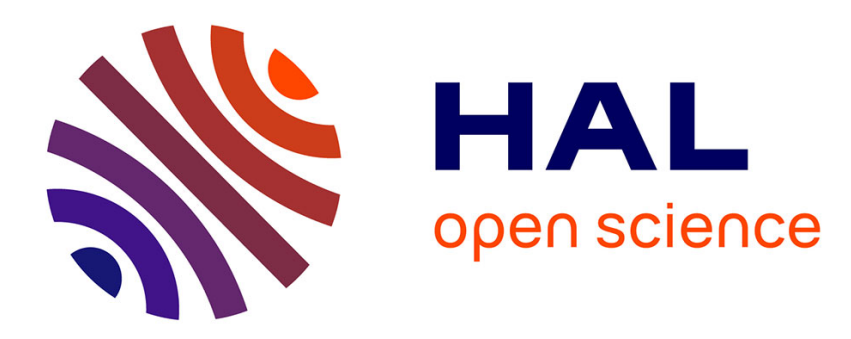

\title{
On the Disequilibrium Dynamics of Sequential Monetary Economies
}

\author{
Sander van Der Hoog
}

\section{To cite this version:}

Sander van Der Hoog. On the Disequilibrium Dynamics of Sequential Monetary Economies. Journal of Economic Behavior and Organization, 2008, 68 (3-4), pp.525. 10.1016/j.jebo.2008.06.008 . hal00643020

\section{HAL Id: hal-00643020 \\ https://hal.science/hal-00643020}

Submitted on 21 Nov 2011

HAL is a multi-disciplinary open access archive for the deposit and dissemination of scientific research documents, whether they are published or not. The documents may come from teaching and research institutions in France or abroad, or from public or private research centers.
L'archive ouverte pluridisciplinaire HAL, est destinée au dépôt et à la diffusion de documents scientifiques de niveau recherche, publiés ou non, émanant des établissements d'enseignement et de recherche français ou étrangers, des laboratoires publics ou privés. 


\section{Accepted Manuscript}

Title: On the Disequilibrium Dynamics of Sequential Monetary Economies

Author: Sander van der Hoog

PII: $\quad$ S0167-2681(08)00132-7

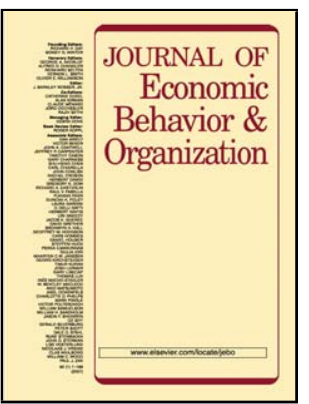

DOI: doi:10.1016/j.jebo.2008.06.008

Reference: $\quad$ JEBO 2229

To appear in: Journal of Economic Behavior \& Organization

Received date: $\quad 9-6-2006$

Revised date: $\quad$ 5-10-2007

Accepted date: $\quad$ 23-6-2008

Please cite this article as: van der Hoog, S., On the Disequilibrium Dynamics of Sequential Monetary Economies, Journal of Economic Behavior and Organization (2007), doi:10.1016/j.jebo.2008.06.008

This is a PDF file of an unedited manuscript that has been accepted for publication. As a service to our customers we are providing this early version of the manuscript. The manuscript will undergo copyediting, typesetting, and review of the resulting proof before it is published in its final form. Please note that during the production process errors may be discovered which could affect the content, and all legal disclaimers that apply to the journal pertain. 


\title{
On the Disequilibrium Dynamics of Sequential Monetary Economies
}

\author{
Sander van der Hoog \\ GREQAM, Château Lafarge, Route des Milles, 13290 Les Milles, France
}

\begin{abstract}
The purpose of this paper is to study the dynamic behavior of a sequential monetary exchange economy. Transactions take place sequentially against non-equilibrium prices, there is quantity rationing, and credit or cash are the only means of exchange. Agents have optimistic or pessimistic expectations about quantity constraints that represent their beliefs about future trading opportunities.

In the credit model the agents incur debts along the transition path towards equilibrium, while in the cash-in-advance model convergence takes place without the occurrence of any debts or claims. The credit mechanism is shown to act as a 'soft' correction mechanism on credit fluctuations, while the cash-in-advance constraint acts as a 'hard' negative feedback effect driving the prices back towards a neighborhood of a monetary cash-in-advance equilibrium.
\end{abstract}

Key words: Circular exchange, trading posts, effective demand, quantity expectations, moving-horizon optimization

JEL classification: C61, D51, D60, E31

\section{Introduction}

An important but still largely unresolved problem in economic theory is the question of stability and the convergence towards equilibrium. It is often assumed that equilibrium prices are generated by a market mechanism that is driven by the law of supply and demand, a model described by the Walrasian tâtonnement process, in which a central price setting mechanism, or market maker, adjusts prices on all markets simultaneously

Email address: svdhoog@gmail.com (Sander van der Hoog). 


\title{
On the Disequilibrium Dynamics of Sequential Monetary Economies
}

\begin{abstract}
The purpose of this paper is to study the dynamic behavior of a sequential monetary exchange economy. Transactions take place sequentially against non-equilibrium prices, there is quantity rationing, and credit or cash are the only means of exchange. Agents have optimistic or pessimistic expectations about quantity constraints that represent their beliefs about future trading opportunities.

In the credit model the agents incur debts along the transition path towards equilibrium, while in the cash-in-advance model convergence takes place without the occurrence of any debts or claims. The credit mechanism is shown to act as a 'soft' correction mechanism on credit fluctuations, while the cash-in-advance constraint acts as a 'hard' negative feedback effect driving the prices back towards a neighborhood of a monetary cash-in-advance equilibrium.
\end{abstract}

Key words: Circular exchange, trading posts, effective demand, quantity expectations, moving-horizon optimization

JEL classification: C61, D51, D60, E31

\section{Introduction}

An important but still largely unresolved problem in economic theory is the question of stability and the convergence towards equilibrium. It is often assumed that equilibrium prices are generated by a market mechanism that is driven by the law of supply and demand, a model described by the Walrasian tâtonnement process, in which a central price setting mechanism, or market maker, adjusts prices on all markets simultaneously based on the demand and supply of all the market participants. It is essentially a nonlinear dynamical system that is driven by a central processing unit that coordinates the decentralized decisions of self-interested, autonomously acting agents.

It is well-known in the literature on (price) adjustment processes that the Walrasian tâtonnement process need not converge to a Walrasian equilibrium. Some examples in which cycles or chaotic behavior are shown to occur are in Scarf (1960), Saari (1985), Goeree et al. (1997), and Tuinstra (2000). 
In dynamic price adjustment processes it is not uncommon to use as the dynamic process a sequence of temporary equilibria. An equilibrium is simply obtained in every period of the process by solving a market-clearing equation, but the question of how such temporary equilibria can be reached as the result of some dynamic disequilibrium process is then usually left unspecified. This fundamental theoretical question refers back to the Stockholm School tradition in disequilibrium modelling, for example Hayek (1928), Lindahl (1939) and Hicks (1939). For general surveys on Disequilibrium Dynamics in the 1930s, see Zappia (2001) and Hansson (1982). A short review of the historical links between the Stockholm School and the literature on Disequilibrium Dynamics in the 1970s is given in van der Hoog (2005).

The simplest model in which disequilibrium trading processes can be studied is in an exchange economy without a production sector or a financial sector. It is a first step towards a more comprehensive theory that explains how equilibria can be reached. The question is also strongly related to the stability of Keynesian or underemployment equilibria under dynamic adjustment processes that take place outside of equilibrium.

In the disequilibrium literature of the 1970s the focus was primarily on the existence, uniqueness and welfare properties of Keynesian equilibria (i.e., fix-price equilibria and quantity constrained equilibria). This was mainly due to the fact that the tools and techniques for the study of nonlinear dynamical systems were not as well developed in the 1970 s as they are today.

In Benassy (1975) mention is made of the fact that in order to integrate money into a disequilibrium framework with rationing of demand and supply, special attention should be paid to the wealth redistribution effects that money has on the out-of-equilibrium behavior of the economy. Later Shubik (1999) also noted that these monetary effects are of a 'peculiarly institutional' nature.

Perhaps one of the reasons that the study of out-of-equilibrium monetary effects was put on hold (and the focus was put instead on fix-price equilibria in which the excess demand for money balances is always in equilibrium) was that the models would become too complicated to remain analytically tractable. Since analytical tractability was the sine qua non for all mathematical economics models in the 1970s, some important research issues were left unexplored in this literature.

Now that the contributions of the research community are more and more tilted towards using agent-based techniques and there is a growing acceptance of using numerical analysis to study complex systems, it seems worthwhile to revisit some of the problems that were discussed but never fully investigated in the disequilibrium literature of the 1970s.

This paper takes the study of Benassy one step further, namely to treat the effects of money in a disequilibrium context with sequential trading. This means that we have to take into account the redistribution effects in a monetary economy that is not fully adjusted to a monetary equilibrium.

We develop a dynamic model in which trade is taking place sequentially and at nonequilibrium prices. We consider both a pure credit economy with only inside money as well as a cash-in-advance economy with outside money. A particular institutional feature that we impose is that there exist only spot markets which re-open sequentially over time. The markets are thus very incomplete, and agents cannot insure themselves against risk (for example by using Arrow securities). A direct motivation for studying such a model is that in the real world not all spot markets may be open simultaneously or that agents 
simply cannot trade on all markets at the same time due to information gathering costs or information processing time.

Clower (1965) relates the Keynesian concept of effective demand to a process of sequential decision-making in his 'Dual-Decision Hypothesis' (henceforth DDH). ${ }^{1}$ An important aspect of the DDH is that it distinguishes between notional demand (without quantity constraints) and effective demand (with quantity constraints). However, since the DDH does not focus on the market structure, it should be interpreted as a behavioral postulate (i.e., it refers to the notion that agents do not plan to spend more than their budget constraint allows them to and therefore sequentially re-optimize in order to take the realized transactions into account).

Besides this behavioral interpretation of the DDH there is another interpretation referring to markets as 'sequential trading posts.' This interpretation is due to Benassy and can also be found in Clower and Leijonhufvud (1975). This postulate states that each market could be seen as a 'trading post' at which only a single commodity can be traded. The agents visit the trading posts in a given trading order and re-optimize their consumption plans between the market visits. Since this refers to a sequential market structure and not as much to the behavioral postulate of the DDH above, this should be seen as a structural postulate about the market structure.

Although the individual trading orders need not be the same for every agent, in the model we have assumed this to be the case for ease of exposition. Agents have to move from one market to the next because trading takes time. Due to the sequential market structure the trading plans need to be revised sequentially, given the new information that is being generated by the trading process. This sequential market structure therefore gives a choice-theoretic rationale for the behavioral postulate of the $\mathrm{DDH}$, and the DDH in turn gives the rationale for using the Keynesian concept of effective demand.

The structure of the model presented here is similar in spirit to the spatial model in Kiyotaki and Wright (1989), henceforth the KW model. However, in the KW model it is not the markets that are spatially separated, but the agents. In our model the markets are topologically located on a circle, which can be referred to as a 'market circle'. A period is defined as one round around the market circle. Figure 1 illustrates this circular exchange economy. Note that in the center of the circle there is a bank since all transactions involve a transfer of credit from buyers to sellers, and credit is perfectly storable on the bank accounts.

\section{[INSERT FIGURE 1 ABOUT HERE]}

Note however that in a large-scale, sequential market model with a very large population of agents (each having its own trading order), trade is taking place on all markets simultaneously, with different agents meeting on different markets. It may then turn out that the simultaneous market model (in which all markets are open and all agents are trading simultaneously on all the markets) is a good approximation for the much more complex sequential market model in which trade takes place synchronously and in parallel on all markets, but individual agents are trading sequentially. The answer to this theoretically important question will require further research in the future. Here we only

\footnotetext{
1 The notion that all consumption decisions are taken simultaneously, including all present and future commodities, was called the 'unified-decision hypothesis' by Clower. If the consumption decisions are taken sequentially, then this is called the 'dual-decision hypothesis'.
} 
consider the sequential trading model with two distinctions, which will lead to different versions of the model (see the categorization in Table 1):

1. Means of exchange: credit (inside money) or cash (outside money);

2. Information updating: sequential updating or end-of-period updating of budget constraints and prices.

All agents in the model are consumers, characterized by utility functions and resource endowments. The initial endowments are the same at the start of every period, reflecting the notion that commodities are perishable. There is no storage facility for the commodities, so there is no carry-over of stocks from one period to the next. This facilitates the analysis considerably since there are no inventories. For the description of the microeconomic decision-making process we stay close to neo-classical consumer theory. We retain the notion of maximizing behavior on the part of the individual agents, but with three important provisos: (i) agents are myopic, (ii) they take into account the possibility of being rationed, and (iii) agents use a moving-horizon optimization procedure.

[INSERT TABLE 1 ABOUT HERE]

\section{Myopic optimization}

The first assumption we make is that agents do not possess the mental capacities to plan ahead for an infinite time-horizon. Instead, agents are myopic utility maximizers, only able to plan ahead for one period. Because the trading environment (prices and quantity constraints) is changing continuously, this leads to the incompatibility of the trading plans and consequently to the revision of plans subject to new information. An equilibrium is then characterized by a situation in which the environment no longer changes and the plans remain the same.

\section{Notional versus effective demand}

The second assumption we make is that agents take into account the fact that they are being rationed. This leads to the concept of effective demand in which expectations about future rationing constraints play a role (Clower 1965). These expectations enter as additional variables into the demand functions, reflecting the sequential nature of the trading process.

The current model with sequential trade is a generalization of the model in Weddepohl (1996). For disequilibrium trade to be possible an endogenous quantity rationing mechanism is needed. Otherwise no transactions can occur, at least not as long as markets are out of equilibrium. For the rationing mechanism we use a proportional rationing rule: the demand or supply orders of the agents on the long side of the market are rationed in proportion to the transaction offers (Benassy 1975). If the agents know that the rationing mechanism is proportional, then this rule can be manipulated by over-asking or over-supplying the market. For simplicity we assume that agents ignore this type of strategic behavior (also short-selling is not allowed). This assumption can be defended on the grounds that the distribution of realized trades can be modelled as the outcome of a random matching process where total excess demand is distributed across the agent population by a stochastic version of the uniform proportional rationing mechanism (see e.g. Green 1980, pp. 348-350, and Weinrich 1988, p. 116). Furthermore, agents are prevented from exaggerating their transaction offers by the fact that they may actually be called upon to transact the quantities they have offered for trade. 
Spill-over effects from rationing play a role in the agents' decision-making process, which are taken into account explicitly by considering the fact that the rationing influences the decisions and the expectations of the agents. The quantity constraints are updated sequentially, and agents determine their effective demand before visiting each market. They take into account that rationing occurred in the past and that it may occur again in the future. What matters for the transactions in the future is not the realized constraints of the past, but the expected constraints for the future. Therefore the expected quantity constraints are added as additional variables in the demand functions of the agents. This allows us to study the influence of pessimistic and optimistic quantity expectations. In particular, in this paper we study whether in the sequential 'trading post' model such quantity expectations have a predominantly destabilizing effect on the out-of-equilibrium price dynamics.

\section{Credit versus cash}

According to Magill and Quinzii (1996, p. 488) a satisfactory modelling of money requires an open-ended future. Trade should take place in a sequence economy in which the imperfections in the trading opportunities of the agents play a role.

The trading possibilities of the agents can be restricted due to multiple transaction constraints, including income, financial or quantity constraints. Such restrictions have consequences in monetary and in real terms. Not only are there spill-over and substitution effects due to trade at disequilibrium prices, but there are also wealth redistribution effects due to the monetary restrictions (i.e. there are cash-in-advance or liquidity effects).

We will investigate the influence of the presence of such a cash-in-advance constraint on the stability properties of the sequential trading process. The trade deficits and trade surpluses that accumulate during a period have to be corrected on the balance of account of the agents. This will affect the agents' budget constraints. Agents must not only repay the old debts that have already accumulated but must also prevent new debts from occurring. If these effects were ignored, then it would be optimal for agents to run into debt indefinitely. For this we require an accounting device. We distinguish between two means of payment:

1. Credit exchange. There is a zero money stock and all transactions are paid for by credit. Trading out of equilibrium causes debts and claims to occur, but these are accounted for by the credit mechanism. Agents who have a debt at the end of a period are held accountable by a correction of their budget for the following period (enforcement of debt repayments).

2. Cash exchange. There is a positive money stock and all transactions are paid for by cash. In addition to the budget constraint there is also a cash-in-advance constraint. The quantity that is to be purchased on the current market is limited by the total amount of cash available to the agent. ${ }^{2}$ There are no longer any debts or claims since the cash balance is not allowed to become negative and cash-in-

\footnotetext{
2 On financial markets such limitations are known as margin requirements, which govern how much of any stock purchase can be made with credit and how much should be paid with cash. A margin requirement of 100 percent would mean a strict cash-in-advance constraint. A margin requirement of 0 percent would imply that stocks can be fully financed with borrowed money. The present requirement is 50 percent; half of any stock purchase can be made with borrowed money, half in cash (see Stiglitz 2003, p. 64).
} 
advance means no cash, no consumption. If an agent has a trade surplus at the end of a period, then this surplus can be spent on consumption immediately.

In a pure credit system, the aggregated money holdings of the agents cancel out as debits and credits. Therefore all that is needed for a pure credit system to function is that agents have agreed upon some unit of account in which to register all debts and claims. We assume that such an agreement has already taken place and that there is a system of bank accounts providing the credit economy with this book-keeping feature.

The difference between the cash exchange process and the credit exchange process is that agents are not allowed to enter into debt (credit arrangements), so the cashin-advance constraint causes agents to become rationed in their demand. In the credit model agents incur debts along the adjustment path, while in the cash model the convergence towards equilibrium takes place without the occurrence of any debts or claims (if convergence in fact occurs).

Sequential updating versus end-of-period updating of budget constraints and prices

The trading period is divided into subperiods, or 'market days'. During each subperiod only one market is visited, so only one good can be traded. The markets are visited in a predetermined order and transactions take place at the prevailing (i.e. fixed) market prices that have been determined during the previous trading period. The model is therefore a fix-price model (Hicks). However, as already noted by Hicks, also in fix-price models prices are not completely fixed for all eternity, but change after some trading period. There is some price stickiness.

Prices are temporarily fixed, but can adjust after the market has been visited. Only the price for the commodity being traded on the current market is updated since the other markets are temporarily closed for trading. After every round of market visits, some economic variables other than market prices can be updated, such as the budget constraint or the expectations of the agents.

We consider two sequential adjustment processes:

1. Inter-period adjustment process: transactions occur sequentially during the period, but all price adjustments occur at the end of a period. The process is reminiscent of Hicks' Fixprice method, also known as single-period analysis; the price-vector remains fixed for a certain period and is adjusted at the end of the period. However, in Hicks' process trade is not allowed at disequilibrium prices, only at a temporary equilibrium. Hicks' process consists of a sequence of temporary equilibria. In contrast, we allow for trade at disequilibrium prices, so our process consists of a sequence of disequilibrium states. We refer to the inter-period adjustment process as an end-of-period process. The process consists of a sequence of quantity adjustments (trades) followed by a single price adjustment step. This refers to the notion attributed to Keynes that quantities adjust faster than prices (see Leijonhufvud 1968, p.52).

2. Intra-period adjustment process: the transactions and price adjustments all occur sequentially during the period. This process is reminiscent of Lindahl's Disequilibrium method, also known as sequence analysis (see Lindahl 1939, and Zappia 2001): prices are announced by sellers at the beginning of the period; trade occurs at disequilibrium prices, so there is quantity rationing; prices adjust instantaneously after every sequential transaction during the period but not necessarily to equilibrium 
levels. The process consists of a sequence of disequilibria with prices and quantities adjusting equally fast and sequentially during the process.

The inter-period adjustment process works as follows. The adjustments of prices and budget constraints (e.g. the cash balances in the cash model) occur at the end of a period. The quantity constraints are updated sequentially since trade is occurring sequentially. This process is referred to as the end-of-period updating process.

The intra-period adjustment process works as follows. A period consists of a sequence of steps in which the transactions occur sequentially until all markets have been visited. Then a new period begins. All agents have exactly the same market order and move from one market to the next. Transactions take place on a market-by-market basis. In other words, the agents are not trading bilaterally, but they are all trading simultaneously and anonymously on a centralized market by submitting their buy and sell offers. The adjustments of the market price, the quantity constraints and the budget constraints all occur after every market visit. The speed at which prices and quantities adjust is equally fast, so the process is a disequilibrium process with sequential adjustments of both prices and quantities. This process is referred to as the sequential updating process.

The only difference between the end-of-period process and the sequential process is that prices (and budget constraints) are updated either at the end of the period or sequentially during the period. Trade is taking place all the time and at disequilibrium prices. Both processes therefore consist of a sequence of disequilibrium states. The end-ofperiod updating of budget constraints implies that agents' subjective information about the state of their balance of account does not change during the current period. When they are taking their consumption decisions, the agents therefore use old information pertaining to their available budget at the beginning of the period since they have not yet updated their budget constraint. In the sequential updating process the subjective information is updated immediately and exactly reflects the objective information about the currently available budget. One of the research questions we address in this paper is whether it matters how often the agents update their budgets and what effect, if any, this has on the stability properties of a monetary equilibrium.

The sequential trading process implies that agents continually have to re-optimize their trading plans in response to the quantity constraints that appear on the market, and the sequence of quantity constraints affects the trading decisions of the agents through spill-overs, which causes situations of disequilibrium. We study the process in terms of the sequence of plans and constraints, with prices and quantities adjusting to the disequilibrium.

The rest of this article is organized as follows. Section 2 introduces the formal model. Section 3 provides simulation results and conclusions for the credit model. Section 4 introduces the cash-in-advance model with Section 5 showing the simulation results. In Section 6 we provide general conclusions, make a comparison between both models and discuss topics for future research.

\section{A formal model}

We consider an exchange economy consisting of $N$ households, $h=1, \ldots, N$, with $m$ non-storable and non-durable commodities that can be traded on $m$ markets, $i=1, \ldots, m$. 
At the beginning of each period an agent has a set of endowments (possibly zero for some commodities). Since there is no storage facility all endowments must either be consumed directly by the original owner or traded and then consumed by a new owner.

The notation for all variables and parameters can be found in Tables 2-3.

[INSERT TABLE 2 ABOUT HERE]

[INSERT TABLE 3 ABOUT HERE]

\subsection{Timing}

Time is discrete and each period is divided into subperiods. In every subperiod only a subset of the goods $i \in\{1, . ., m\}$ can be traded. In this paper we assume throughout that only one market is open per subperiod and that only one good can be traded at each trading post. Therefore the number of subperiods is exactly equal to the number of markets. An important extension to consider would be the case with multiple goods traded per trading post.

The timing of events during a market visit is according to the following Market Visiting Rule (see also Figure 2).

Assumption 1 Market Visiting Rule $\mathbf{M V}(t, i)$ :

1. All agents decide simultaneously on how much to buy or sell on market $i$, given the posted price, their subjective expectations about the quantity constraints on the other markets (excluding market $i$ itself), and their individual money holdings.

2. The buy and sell orders are accumulated to compute the total demand and supply on market $i$.

3. Transactions take place against the prevailing market price $p_{i}$, according to a proportional rationing mechanism.

4. The expectations about the quantity constraints for market $i$ are updated after the transactions have occurred.

5. The credit accounts (or cash holdings) are updated.

6. The price for commodity $i$ is updated.

A period is defined as one trading round consisting of a visit to each market, according to the following Trading Round Rule.

Assumption 2 Trading Round Rule TR $(t)$ :

- Execute the Market Visiting Rule $\mathbf{M V}(t, 1)$ for market 1.

- Repeat for each market $i=2, \ldots, m$.

A simulation of the model consists of multiple trading rounds, according to the following Simulation Rule.

Assumption 3 Simulation Rule SR:

- Execute the Trading Round Rule $\mathbf{T R}(t)$ for $t=1, \ldots, T$ periods.

The trading mechanisms are described in more detail in the following sections, reflecting the order of events in the Market Visiting Rule.

[INSERT FIGURE 2 ABOUT HERE] 


\subsection{Moving-horizon optimization}

Let us consider households that are myopic moving-horizon optimizers. These agents do not optimize over an infinite horizon, but have finite planning horizons. As explained before, we assume that the length of the horizon is precisely one period; in other words it consists of a sequence of market visits such that each commodity is traded once per trading period. To illustrate, consider the analogy of the Hicksian Week. Households have some preference for consumption on Monday $\left(c_{1}^{h}\right)$, consumption on Tuesday $\left(c_{2}^{h}\right)$, and so on for every day of the week (or month, or year, etc.). The length of the planning horizon can be heterogeneous across the agents, but we consider it to be homogeneous for ease of exposition.

The consumption plan of an agent in this economy thus consists of a sequence of consumption moments. The sequence is denoted by $\mathbf{c}^{h}=\left\{c_{i}^{h}\right\}_{i=1}^{m}$, where each $c_{i}^{h} \in \mathbb{R}_{+}^{\ell}$, $\ell \geq 1$, can be scalar or vector valued, depending on how many goods can be traded at a single trading post. Here we only consider the case $l=1$ (one good traded per trading post), but there is no reason this could not be extended to the general case $\ell>1$ (see the final section on future research). Similarly, the endowment sequence is defined by $\mathbf{w}^{h}=\left\{w_{i}^{h}\right\}_{i=1}^{m} \in \mathbb{R}_{+}^{l \times m}$. Only the first element $c_{1}^{h}$ of the planned sequence $\mathbf{c}^{h}$ is the desired consumption expressed on the market at date 1; the rest of the sequence remains as planned future consumption. Since plans may change, after each trading day every household re-optimizes their consumption plan leading to an entirely new sequence $\left\{c_{i}^{\prime h}\right\}_{i=1}^{m}$. At date 2 , only $c_{2}^{\prime h}$ is the desired consumption that is expressed on the market at date 2 .

The procedure of subsequently revising consumption plans subject to new information is referred to in this paper as 'moving-horizon optimization'. Weddepohl (1996) referred to it as 'gliding optimization'. It is similar to closed-loop feedback control known from operations research and optimal control theory. However, in that literature it is used as a principle of optimality, while we use it as a behavioral postulate. See Table 4 for an illustration of the moving-horizon optimization procedure.

[INSERT TABLE 4 ABOUT HERE]

\subsection{Optimization problem}

The optimization problem for market $i$ is a simple utility maximization subject to the expected quantity constraints $\tilde{\ell}_{j}^{h}$ and $\tilde{u}_{j}^{h}$ (to be explained in more detail in Section 2.5 and 2.6) and the budget constraint, which is always one period ahead: ${ }^{3}$

$$
\begin{array}{ll}
\max _{\mathbf{c}^{h}} U^{h}\left(\mathbf{c}^{h}\right) & \\
\sum_{j=1}^{m} p_{j} \cdot c_{j}^{h} \leq \sum_{j=1}^{m} p_{j} \cdot w_{j}^{h}+\tilde{M}^{h} & \\
\tilde{\ell}_{j}^{h} \leq c_{j}^{h}-w_{j}^{h} \leq \tilde{u}_{j}^{h}, & \forall j \neq i \\
c_{j}^{h} \geq 0, & \forall j=1, \ldots, m .
\end{array}
$$

$\overline{3 \text { We let }} x_{-i}$ denote the vector $x$ without the value for market $i: x_{-i}=\left(x_{1}, \ldots, x_{i-1}, x_{i+1}, \ldots, x_{m}\right)$. 
The term $\tilde{M}^{h}$ on the right-hand-side of the budget constraint represents a correction for possible debts or claims that accumulated during the previous period (see Section 2.7). Note that the constraints $\left(\tilde{\ell}_{i}^{h}, \tilde{u}_{i}^{h}\right)$ for market $i$ are not included into the optimization problem since the agents still have to submit their orders to market $i$ before the constraints on market $i$ can be determined by the rationing mechanism (see Section 2.4).

Consumption demand on market $i$ is $c_{i}^{h}\left(\mathbf{p}, \tilde{M}^{h}\right)$, and the value $p_{i} c_{i}^{h}$ is the demand for net balances for current consumption. The effective excess demand is defined as $\tilde{z}_{i}^{h}=$ $c_{i}^{h}-w_{i}^{h}$, according to the following effective demand rule:

Assumption 4 Effective Demand Rule E:

$$
\tilde{z}_{i}^{h}:=\mathbf{E}_{i}^{h}\left(\mathbf{p}, \tilde{\ell}_{-i}^{h}, \tilde{u}_{-i}^{h}, \tilde{M}^{h}\right) .
$$

Strictly speaking the effective excess demand is a function of all parameters. To simplify the notation, we will suppress this full parameter dependency and write $\tilde{z}_{i}^{h}\left(\mathbf{p}, \tilde{M}^{h}\right)$. If $p_{i} \tilde{z}_{i}^{h}\left(\mathbf{p}, \tilde{M}^{h}\right)>0(<0)$ then the agent is a net borrower (net lender). The amount of credit that an agent can borrow/lend is exactly equal to the amount of credit an agent subjectively expects to be able to repay/claim in the future. This amount is given by the monetary value of the individual effective excess demands on all the other markets:

$$
\mathbf{p}_{-i} \cdot \tilde{\mathbf{z}}_{-i}^{h}\left(\mathbf{p}, \tilde{M}^{h}\right) \equiv \sum_{j \neq i} p_{j} \cdot \tilde{z}_{j}^{h}\left(\mathbf{p}, \tilde{M}^{h}\right)
$$

where $\tilde{\mathbf{z}}_{-i}^{h}\left(\mathbf{p}, \tilde{M}^{h}\right)=\left(\tilde{z}_{1}^{h}, \ldots, \tilde{z}_{i-1}^{h}, \tilde{z}_{i+1}^{h}, \ldots, \tilde{z}_{m}^{h}\right)$. This ensures that planned demand always satisfies the budget constraint (i.e. planned net borrowing by agent $h$ for consumption on market $i$ is equal to the monetary term $\tilde{M}^{h}$ ):

$$
\sum_{j=1}^{m} p_{j} \cdot \tilde{z}_{j}^{h}\left(\mathbf{p}, \tilde{M}^{h}\right) \leq \tilde{M}^{h}
$$

Thus if $\tilde{M}^{h}>0(<0)$ then the agent plans to spend more (less) on his consumption during the ensuing period than the value of his total endowments since he has a claim (debt) that he can cash-in (needs to repay). In an exchange economy with only interpersonal credit, all transactions are quid pro quo, so the total net borrowing in the private sector is always in equilibrium:

$$
\sum_{h=1}^{N} \sum_{j=1}^{m} p_{j} \cdot \tilde{z}_{j}^{h}\left(\mathbf{p}, \tilde{M}^{h}\right)=\tilde{M}^{1}+\ldots+\tilde{M}^{N} \equiv 0 .
$$

This is true since all the claims and debts in the private sector add up to zero.

\subsection{Rationing mechanism}

Since agents are trading continually, and not just against equilibrium prices, there is quantity rationing. The rationing mechanism we will use is a very basic notion of rationing in which the buy and sell orders can be entered only against the prevailing market prices (all the orders are market orders), and the rationed demand is proportional to the order that was entered.

In order to use any form of rationing we need to aggregate the demand and supply: 
Assumption 5 Aggregation Rule AGG:

$$
\begin{gathered}
d_{i}^{h}=\max \left\{0, \tilde{z}_{i}^{h}\right\}, D_{i}=\sum_{h} d_{i}^{h}, \\
s_{i}^{h}=\min \left\{0, \tilde{z}_{i}^{h}\right\}, S_{i}=-\sum_{h} s_{i}^{h} .
\end{gathered}
$$

Note that the total supply is defined as a positive quantity. The rationing mechanism is described by the following proportional rationing rule:

Assumption 6 Proportional Rationing Rule F:

1. If $D_{i} \geq S_{i}$ then $\left(D_{i} / S_{i}\right) \geq 1$ and

$$
\bar{z}_{i}^{h}= \begin{cases}\left(S_{i} / D_{i}\right) \tilde{z}_{i}^{h} & \text { for } \tilde{z}_{i}^{h} \geq 0 \\ \tilde{z}_{i}^{h} & \text { for } \tilde{z}_{i}^{h} \leq 0 .\end{cases}
$$

2. If $D_{i} \leq S_{i}$ then $\left(D_{i} / S_{i}\right) \leq 1$ and

$$
\bar{z}_{i}^{h}= \begin{cases}\tilde{z}_{i}^{h} & \text { for } \tilde{z}_{i}^{h} \geq 0 \\ \left(D_{i} / S_{i}\right) \tilde{z}_{i}^{h} & \text { for } \tilde{z}_{i}^{h} \leq 0 .\end{cases}
$$

Since the total demand and supply depend on all the transaction offers that are entered by all market participants, we shall use the following shorthand notation for this rationing mechanism: $\bar{z}_{i}^{h}=\mathbf{F}_{i}^{h}\left(\tilde{z}_{i}^{1}, \ldots, \tilde{z}_{i}^{N}\right)$ (see Benassy).

\subsection{Perceived quantity constraints}

As was already noted by Clower (1965), the relevant market signals for an adjustment process are based on the effective demands and not on the notional demands as used in a Walrasian tâtonnement process. This leads to considering different kinds of adjustment processes, so called non-Walrasian tâtonnement processes with mixed price and quantity adjustments, which are also sometimes labelled Keynesian tâtonnement processes.

Let $\ell_{i}^{h} \leq 0$ denote a lower bound on individual excess demand (a supply constraint) and $u_{i}^{h} \geq 0$ denote an upper bound (a demand constraint). The individual (desired) excess demand is restricted by the constraints: $\ell_{i}^{h} \leq \tilde{z}_{i}^{h} \leq u_{i}^{h}$. Agents only perceive rationing constraints if they are actually experiencing binding constraints on a market; otherwise they do not perceive that they are being rationed. The perceived constraints are derived from the realized transactions $\bar{z}_{i}^{h}$ according to the following perceived constraints rule:

Assumption 7 Perceived Constraints Rule G:

$$
\begin{array}{r}
\text { If } \tilde{z}_{i}^{h}<0 \text { and } \sum_{h} \tilde{z}_{i}^{h}<0 \text { then }\left(\ell_{i}^{h}, u_{i}^{h}\right)=\left(\bar{z}_{i}^{h},+\infty\right) ; \\
\text { If } \tilde{z}_{i}^{h}>0 \text { and } \sum_{h} \tilde{z}_{i}^{h}>0 \text { then }\left(\ell_{i}^{h}, u_{i}^{h}\right)=\left(-\infty, \bar{z}_{i}^{h}\right) . \\
\text { else }\left(\ell_{i}^{h}, u_{i}^{h}\right)=(-\infty,+\infty) .
\end{array}
$$

The following shorthand notation is used for this rule: $\left(\ell_{i}^{h}, u_{i}^{h}\right)=\mathbf{G}_{i}^{h}\left(\tilde{z}_{i}^{h}, \bar{z}_{i}^{h}\right)$. 


\subsection{Expectations}

Before an agent comes to a market, he has certain expectations about trading possibilities. These expectations, positive or negative, reflect the agents' beliefs about the economy. When agents are pessimistic they believe that the economy is going to contract and their trading possibilities will worsen. When agents are optimistic they believe that the economy is going to expand (i.e. grow) and that their trading possibilities will improve. The expectations about $(\ell, u)$ are expressed as linear functions by the following rule:

Assumption 8 Quantity Constraints Expectations Rule $\mathbf{H}$ :

$$
(\tilde{\ell}, \tilde{u})=(\beta \cdot \ell, \beta \cdot u) \equiv \mathbf{H}(\ell, u) .
$$

Here $(\tilde{\ell}, \tilde{u})=\left(\tilde{\ell}^{1}, \ldots, \tilde{\ell}^{N} ; \tilde{u}^{1}, \ldots, \tilde{u}^{N}\right) \in \mathbb{R}^{N m} \times \mathbb{R}^{N m}$ is the vector of all expectations; $\left(\tilde{\ell}^{h}, \tilde{u}^{h}\right) \in \mathbb{R}^{m} \times \mathbb{R}^{m}$ are the expected constraints for agent $h$. The expectations parameter $\beta$ measures the degree of optimism/pessimism of the agents: $0<\beta<1$ means pessimism, $\beta>1$ means optimism, and $\beta \rightarrow+\infty$ indicates euphoria, or a belief in unlimited growth. In this case, agents believe that they can transact any quantities they desire (i.e. they use a notional demand function to determine their optimal transaction offers). It would also be interesting to investigate the effect of heterogeneity in the expectations parameter. For example, agents could be optimistic or pessimistic about different markets, or different agents may vary in their degree of optimism or pessimism. Here we let all agents have the same expectations parameter: $\beta_{i}^{h}=\beta$ for all $h, i$.

\subsection{Updating the budget constraint in the credit process}

In this section we describe how the budget constraint is updated by the term $\tilde{M}^{h}$ in the optimization problem (1). In a disequilibrium model with infinitely lived agents wealth effects play an important role since trade takes place outside equilibrium and therefore debt and claims accumulate over time. The repayment of debts then becomes relevant, so an updating procedure for the budget constraints is needed. The frequency at which the re-enforcement of debt repayment is performed can have a large impact on the dynamics since there are nominal and real wealth effects for the individual traders. In this section we shall show how agents sequentially update their budget constraints to take into account these debts and claims.

To recall the notation of time, a period consists of $m$ distinct subperiods in which the markets can be visited sequentially. A period is a time-interval $[t, t+1)$ starting at time $t$ and ending at time $t+1$. It is denoted by $\{(t, 1),(t, 2), \ldots,(t, m)\}$, where $(t, i)$ denotes the (period, subperiod)-index for the market visit $i$ during the period.

The balance of account of agent $h$ at the beginning of subperiod $(t, 1)$ is denoted by $M^{h}(t, 1)$. It can be positive or negative, depending on whether the agent has a debt or a claim on the other agents. The balance of account is the sum of net revenues up to and including the last transaction during the previous market visit. The net revenues for agent $h$ at market $i$ is just the value of the transaction $\bar{z}^{h}(t, i)$, where $(t, i)$ denotes the (period, subperiod)-index:

$$
R^{h}(t, i)=-p(t, i) \bar{z}^{h}(t, i) \quad i=1, \ldots, m .
$$


The balance of account is updated sequentially. After visiting market $i$ the balance is updated by the rule:

$$
M^{h}(t, i+1)=M^{h}(t, i)+R^{h}(t, i) .
$$

Note that the balance of account $M^{h}(t, i+1)$ is determined at the beginning of market $i+1$ (or, equivalently, at the end of market $i$ ). The balance of account at the beginning of a period evolves according to the sum of net revenues:

$$
M^{h}(t+1,1)=M^{h}(t, 1)+\sum_{i=1}^{m} R^{h}(t, i) .
$$

Sequential updating of the budget constraint

The sequential market structure makes it necessary to distinguish between the evolution of the actual balance of account $M^{h}$ and a correction for unanticipated debts and claims $\tilde{M}^{h}$ during the trading process. The term $\tilde{M}^{h}$ is a correction on the budget constraint used by the agents as a 'rule of thumb' in their decision-making process. Define $\Delta M^{h}(t, i)$ to denote the net revenues measured over a moving time-horizon:

$$
\Delta M^{h}(t, i) \equiv M^{h}(t, i)-M^{h}(t-1, i) .
$$

The budget has to be corrected for debts if $\Delta M^{h}(t, i)<0$, or for wealth claims if $\Delta M^{h}(t, i)>0$. This represents the debts or claims that resulted from disequilibrium trading that were unanticipated and unintentionally accumulated by the agents. After visiting market $i$, the sequential correction of the budget constraint at the beginning of subperiod $i+1$ is defined as follows:

$$
\tilde{M}_{\text {(sequential) }}^{h}(t, i+1) \equiv M^{h}(t, 1)+\Delta M^{h}(t, i) .
$$

This is the term that is added to the right-hand-side of the budget constraint in agents' sequential optimization problem in (1).

\section{Interpretation of the correction for unanticipated debts and claims}

In the sequential updating procedure, agents get information about their actual balance of account after every transaction. Due to the sequence of transactions during a period, the actual balance of account $M^{h}$ shows fluctuations, even in equilibrium. However, the agents do not accumulate any debts or claims in an equilibrium, so for the unanticipated debts and claims we have that $\tilde{M}^{h}=0$ in equilibrium. The equilibrium fluctuations of $M^{h}$ should not affect the plans; therefore $M^{h}$ should not be entered on the right-hand side of the budget constraint directly, and we should use the correction term $\tilde{M}_{\text {(sequential) }}^{h}$ instead.

For this reason, it is necessary to let agents look back one complete period at every re-optimisation step. Since there is no money stock, but only credit, and since every agent starts without any debts or claims, we have that $\sum_{h} M^{h}(t, i)=0$ for all subperiods $(t, i)$. Hence, also $\sum_{h} \Delta M^{h}=0$ and $\sum_{h} \tilde{M}^{h}=0$, which reflects the fact that the private sector loans market is in equilibrium. The budget constraint is continually updated as agents recalculate and re-optimize their consumption plans. Due to the sequential nature of the trading mechanism, agents immediately perceive that they are accumulating debts or claims using this moving horizon correction, and this is immediately taken into account in the budget constraints. 


\section{End-of-period updating of the budget constraint}

Suppose that agents only update their budget constraint at the end of a round. Then in the optimization problem the planned trade vector $\mathbf{z}^{h}$ at subperiod $(t, i)$ satisfies the following budget constraint:

$$
\mathbf{p}(t, i) \cdot \mathbf{z}^{h}(t, i) \leq \tilde{M}_{\text {(end-of-period) }}^{h}(t, i), \quad \text { for all } i=1, \ldots m,
$$

where we set $\tilde{M}_{\text {(end-of-period) }}^{h}(t, i):=M^{h}(t, 1)$ for all $i=2, \ldots m$. That is, in the end-ofperiod updating model the correction term for the budget constraint remains equal to the start-of-period money holdings $M^{h}(t, 1)$ during the entire period. It is not updated during the period, but is updated only at the start of the next period. Thus, during the period the right-hand-side of the budget constraint remains constant, while the actual balance of account $M^{h}(t, i)$ still fluctuates. This implies that the subjective information being used by the agent does not correspond to the objective information (the actual position of the account), and the agent clearly has some bounded rationality. Since the value of $M^{h}(t, 1)$ is given at the beginning of subperiod $(t, 1)$, it can be treated as a parameter in the optimization problem of subperiod $(t, 1)$ and in the optimization problems of the subsequent subperiods. At the beginning of the next period the correction term is reset to the new true balance of account:

$$
\tilde{M}_{\text {(end-of-period) }}^{h}(t+1, i):=M^{h}(t+1,1), \quad \text { for all } i=1, \ldots m .
$$

An interpretation for the end-of-period updating of the budget constraints is that the agents recalculate their budget constraint at the start of each new period, but not during the period, taking into account the debts and claims that have accumulated over the previous period. This version of the model combines a slow time-scale for the updating of the budget constraints (a low updating frequency) and a fast time-scale for the process of transactions (a high updating frequency). Note further that this updating mechanism only affects the frequency at which budget constraints are updated, not the frequency at which plans are made. Every market visit involves new plans being made at the same frequency as trades occur since the quantity constraints adjust and the agents take into account that they experienced rationing when they revise their plans and expectations.

The price updating frequency is assumed to follow the updating frequency of the budget constraints, although this is not strictly necessary. This assumption is made for convenience since otherwise the number of model variations would be doubled. Agents observe an entirely new price vector at the beginning of each new period. The specification of the sequential price updating mechanism follows below.

\subsection{Sequential price dynamics}

In the sequential trading process the price adjustments are taking place sequentially, instead of simultaneously for all the markets at once. Let $f_{i}$ denote some price adjustment function for the price on market $i$, which necessarily must be a function of the entire price vector since the agents' trading plans are a function of all prices. Recall that the price-vector $\mathbf{p}(t, 1)$ is given at the start of subperiod $(t, 1)$, and the price on market 1 is updated after market 1 has been visited, but before market 2 opens for trade. Therefore, the announced new price for market 1 is $p_{1}(t, 2)=f_{1}(\mathbf{p}(t, 1))$. The price dynamics in the sequential updating process evolve according to the following rule: 
Assumption 9 Sequential Price Updating Rule P:

$$
\begin{aligned}
\mathbf{p}(t, 1) & \equiv\left(p_{1}(t, 1), p_{2}(t, 1), \ldots, p_{m}(t, 1)\right) \\
\mathbf{p}(t, 2) & =\left(f_{1}(\mathbf{p}(t, 1)), p_{2}(t, 1), \ldots, p_{m}(t, 1)\right) \\
\mathbf{p}(t, 3) & =\left(f_{1}(\mathbf{p}(t, 1)), f_{2}(\mathbf{p}(t, 2)), p_{3}(t, 1), \ldots, p_{m}(t, 1)\right) \\
& \vdots \\
\mathbf{p}(t, j+1) & =\left(f_{1}(\mathbf{p}(t, 1)), f_{2}(\mathbf{p}(t, 2)), \ldots, f_{j}(\mathbf{p}(t, j)), p_{j+1}(t, 1), \ldots, p_{m}(t, 1)\right) \\
& \vdots \\
\mathbf{p}(t+1,1) & =\left(f_{1}(\mathbf{p}(t, 1)), f_{2}(\mathbf{p}(t, 2)), \ldots, f_{m}(\mathbf{p}(t, m))\right) .
\end{aligned}
$$

It is clear that this system is not yet written in closed-form, but it can be turned into a simultaneous system of difference equations by substituting the first equation into the second, the first and second into the third, and so on. This does not alter the dimension of the system, which remains $m$-dimensional.

\section{Proportional price adjustments}

We will use proportional price adjustments that are based on the ratio of aggregate market demand and aggregate market supply. We assume that the price mechanism is the same on all markets, $f_{i}=f$, and that prices adjust according to the following price adjustment rule: ${ }^{4}$

Assumption 10 Price Adjustment Rule DS:

$$
p_{i}(t, i+1)=p_{i}(t, i)\left(\frac{D_{i}(\mathbf{p}(t, i))}{S_{i}(\mathbf{p}(t, i))}\right)^{\lambda_{i}} \equiv f_{i}(\mathbf{p}(t, i)), \text { with } \lambda_{i} \geq 0 .
$$

This price adjustment rule has the property that $p_{i}(t, i+1)=p_{i}(t, i)$ if and only if $D_{i}(t, i)=S_{i}(t, i)$, for all $\lambda_{i}>0$. Hence in equilibrium prices do not change. The parameter $\lambda_{i}$ is the 'speed of adjustment' parameter, which plays a crucial role for the stability of the price process. It can be interpreted as the price flexibility. We assume that the price flexibility is the same on all markets: $\lambda_{i}=\lambda$. High values of $\lambda$ indicate that prices are very flexible, low values of $\lambda$ indicate that prices are rigid, and $\lambda=0$ means that prices are completely fixed. The price flexibility can be assumed to be homogeneous across markets without loss of generality by a rescaling of the units in which the quantities of commodities are measured. Since a priori there are no theoretical arguments for the value of the parameter $\lambda$, we will use it as a bifurcation parameter to investigate the stability of the dynamics with respect to changes in the price flexibility. Another nice property of the DS-rule is that it can be transformed into a log-transformation of the classical discrete-time version of the tâtonnement process that is often used in the literature: $\left[p_{i}(t+1, i)-p_{i}(t, i)\right] / p_{i}(t, i)=\lambda z_{i}(t, i)$. Taking the logarithm on both sides of the DSrule, we obtain

$$
\log \left(p_{i}(t+1, i)\right)-\log \left(p_{i}(t, i)\right)=\lambda \cdot\left(\log \left(D_{i}(t, i)\right)-\log \left(S_{i}(t, i)\right)\right),
$$

\footnotetext{
4 This proportional price rule can also be derived from the ratio of excess demand over total market supply: $p_{i}(t+1, i)=p_{i}(t, i)\left(1+z_{i}(t, i) / S_{i}(t, i)\right)=p_{i}(t, i)\left(1+\left(D_{i}(t, i)-S_{i}(t, i)\right) / S_{i}(t, i)\right)=$ $p_{i}(t, i)\left(D_{i}(t, i) / S_{i}(t, i)\right)$.
} 
which is linear in both log-demand and log-supply.

\section{Price normalization}

Since nominal price levels are indeterminate, we normalize prices using a simplexnormalization rule. The real-balance effect (the effect that old debts denominated in the old currency become 'cheaper' in terms of purchasing power when the price level increases) should not affect the agents' demand for commodities since the demand functions are homogeneous. The purchasing power of the old balances should remain constant in real terms if all prices are normalized by the normalization rule. Therefore we will also re-normalize the balances by the same normalization rule.

The budget constraint after normalization (i.e., the real wealth consisting of (i) the value of possessions $\mathbf{p w}^{h}$ and (ii) the initial real balances $M^{h}$ ) is given by

$$
\frac{\mathbf{p} \cdot \mathbf{x}^{h}}{N(\mathbf{p}) / c} \leq \frac{\mathbf{p} \cdot \mathbf{w}^{h}}{N(\mathbf{p}) / c}+\frac{M^{h}}{N(\mathbf{p}) / c}, \text { where } N(\mathbf{p})=\sum_{i=1}^{m} p_{i} .
$$

The last term is the normalization of the real balance of account. In simulations we have used the normalization rule $\sum p_{i}=3$ since all the examples we consider have three markets; hence $c \equiv m=3$. The normalization is performed after every change in the price-vector (i.e. after every sequential market visit).

\section{Price growth restrictions}

Institutional constraints might prohibit prices from fully adjusting to equilibrium values. Therefore we introduce price rigidities in the form of 'ceilings' and 'floors' on the growth rates of prices. Such rigidities prevent nominal prices from imploding or exploding and keep the nominal price fluctuations bounded within economically meaningful regions. The economic arguments for introducing such restrictions in the model are twofold. Following Weddepohl (1995), they can be justified as 'cautious price adjustments' by the sellers. A seller, cautious not to adjust its price too much, uses a self-imposed pricing restraint. A second justification is that there are nonlinear price adjustment costs. For every price adjustment involves some fixed costs (for example, for printing a new price catalogue or changing all the price tags), but large price adjustments might be more costly than small incremental changes.

Let the price growth factor be measured by $\pi_{i}(t+1, i) \equiv p_{i}(t+1, i) / p_{i}(t, i)$. We define the growth rigidities by $\pi_{i}^{+}=\left(1+r^{+}\right)$and $\pi_{i}^{-}=\left(1-r^{-}\right)$, where $r^{+}$and $r^{-}$are the maximum rates of positive and negative growth, respectively. The upward and downward price rigidities are then given by the following restrictions:

$$
\pi_{i}^{-} \leq \pi_{i}(t+1, i) \leq \pi_{i}^{+}, \quad\left(1-r^{-}\right) \leq \frac{p_{i}(t+1, i)}{p_{i}(t, i)} \leq\left(1+r^{+}\right) .
$$

In terms of growth rates in log-prices, the price rigidities are linear restrictions, and the following are equivalent:

$$
\begin{array}{rlrl}
\log \pi_{i}^{-} & \leq \log \pi_{i}(t+1, i) & \leq \log \pi_{i}^{+} \\
\log \left(1-r^{-}\right) & \leq \log p_{i}(t+1, i)-\log p_{i}(t, i) \leq \log \left(1+r^{+}\right) \\
-r^{-} & \leq \log p_{i}(t+1, i)-\log p_{i}(t, i) \leq r^{+} .
\end{array}
$$


The last line follows since $\log (1+x)=x$ to a first approximation. Due to the derivation we obtained in Eq. 23 for the proportional price adjustment rule (22) in terms of log-prices, we can now relate the proportional price changes to proportional changes in quantities, as follows:

$$
\pi_{i}(t+1, i)=\min \left\{\pi_{i}^{+}, \max \left\{\pi_{i}^{-},\left(D_{i}(t, i) / S_{i}(t, i)\right)^{\lambda}\right\}\right\} .
$$

Redefining the restrictions to take the parameter $\lambda$ into account, we obtain new bounds: $\eta^{-}=\left(-r^{-} / \lambda\right)$ and $\eta^{+}=\left(r^{+} / \lambda\right)$. The log-price changes are now restricted by the loggrowth rates $\eta^{-}$and $\eta^{+}$(note that $\lambda$ no longer appears in the restrictions due to the re-parametrization):

$$
\log \frac{p_{i}(t+1, i)}{p_{i}(t, i)}= \begin{cases}\lambda \log \left(D_{i}(t, i) / S_{i}(t, i)\right), & \text { if } \eta^{-} \leq \log \left(D_{i}(t, i) / S_{i}(t, i)\right) \leq \eta^{+} \\ -r^{-}, & \text {if } \log (D / S) \leq \eta^{-} \\ r^{+}, & \text {if } \log (D / S) \geq \eta^{+} .\end{cases}
$$

The terms $\eta^{-}$and $\eta^{+}$simultaneously take into account the effect of the price adjustment speed $\lambda$ and the restrictions $r^{+}$and $r^{-}$respectively, and they can be interpreted as the minimum and maximum growth rates in log-prices. As can be expected, in simulations we observe that the price restrictions become binding more often when prices are more flexible.

\section{Simulation of the credit model}

Having described all the market mechanisms we can now show simulation results. Figure 3 provides a pseudo code that encodes the market mechanisms into a computational algorithm.

\section{[INSERT FIGURE 3 ABOUT HERE]}

\subsection{Example: CES utility}

We consider an example with $N=3$ agents and $m=3$ commodities. There is no cash money, only credit (inside money): $M^{h}(0,1)=0$. All agents have CES utility functions with the same elasticity of substitution parameter $\nu \in(-\infty, 1]$ :

$$
\begin{aligned}
& U^{a}\left(x^{a}\right)=\left[0.2\left(x_{1}^{a}\right)^{\nu}+0.5\left(x_{2}^{a}\right)^{\nu}+0.3\left(x_{3}^{a}\right)^{\nu}\right]^{1 / \nu}, w^{a}=(100,0,0), M^{a}(0,1)=0, \\
& U^{b}\left(x^{b}\right)=\left[0.3\left(x_{1}^{b}\right)^{\nu}+0.2\left(x_{2}^{b}\right)^{\nu}+0.5\left(x_{3}^{b}\right)^{\nu}\right]^{1 / \nu}, w^{b}=(0,100,0), M^{b}(0,1)=0, \\
& U^{c}\left(x^{c}\right)=\left[0.5\left(x_{1}^{c}\right)^{\nu}+0.3\left(x_{2}^{c}\right)^{\nu}+0.2\left(x_{3}^{c}\right)^{\nu}\right]^{1 / \nu}, w^{c}=(0,0,100), M^{c}(0,1)=0 .
\end{aligned}
$$

The preference parameters $\alpha$ and endowments $w$ have been chosen symmetrically such that in equilibrium there is one seller and two buyers on each market and the equilibrium price vector is symmetric: $\mathbf{p}^{\star}=(1,1,1)$. For the Cobb-Douglas case $(\nu=0)$, the equilibrium consumption demand and the excess demand are given by 


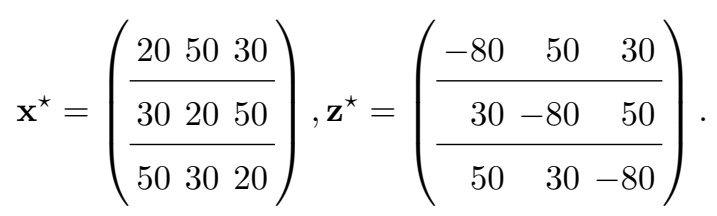

Figure 4 shows the individual balance of account for agent 1 , on markets $1,2,3$. In a steady state equilibrium these plots would show a single point since they show the balance at the start of every market visit. Figure 5 shows the corresponding price dynamics and excess demand dynamics, for 50 consecutive periods along a quasi-periodic attractor. The prices fluctuate around the equilibrium values $p_{i}^{\star}=1$, and the balance of account fluctuates around the equilibrium values $M^{1}(t, 1)=0, M^{1}(t, 2)=80, M^{h}(t, 3)=30$. The same values hold mutatis mutandis for agents 2 and 3 .

[INSERT FIGURE 4 ABOUT HERE]

[INSERT FIGURE 5 ABOUT HERE]

\subsection{End-of-period credit process}

The coexistence of attractors and a hysteresis effect

Figure 6a shows that a steady state appears stable for all substitution parameter values $\nu \leq 0$. For values $\nu>0$ periodic and quasi-periodic orbits suddenly appear. In Figure $6 \mathrm{~b}$ the bifurcation occurs at a lower value of the elasticity of substitution parameter $\nu$.

These bifurcation diagrams in Figure 6a-b are not produced with a unique initial condition, but the attractor is traced as long as it remains locally stable. In this tracing procedure the final point of an orbit is taken as the new initial condition for the next parameter run. The final point is slightly perturbed to prevent a lock-in into an unstable branch (i.e. when the attractor has become a repeller).

The bifurcation diagram in Figure 6a has been produced from "left-to-right" by increasing the bifurcation parameter from $\nu=-0.5$ to $\nu=0.6$. The diagram in Figure $6 \mathrm{~b}$ has been produced from "right-to-left" by decreasing the bifurcation parameter from $\nu=0.6$ to $\nu=-0.5$.

The steady state and periodic cycles co-exist for parameter values $-0.2<\nu<0$. Notice that in the parameter region $-0.2<\nu<0$ there now exists a quasi-periodic attractor that we did not observe in Figure $6 \mathrm{a}$. The steady state and the quasi-periodic attractor co-exist at the same parameter values, but appear for different initial conditions. The occurrence of multiple attractors raises the possibility of a hysteresis effect, also sometimes called 'system memory': changing a certain parameter will lead to a different attractor because the system jumps to a different basin, but changing the parameter back to its original value does not produce the original attractor because the system 'remembers' the parameter change (see the appendix for a technical discussion, available in the on-line version of this journal).

In Figure 6 (top diagram) we observe such a hysteresis effect in the credit model. A period 12-cycle suddenly becomes visible (it was already stable) as the system jumps from the steady state to the stable branch of the cycle: the system jumps from the basin of the steady state to the basin of the 12-cycle. This jump occurs as the parameter crosses the jump point at $\nu=0$. When we decrease the parameter from right-to-left, then the 
period 12-cycle remains locally stable until the system jumps back to the steady state at $\nu=-0.2$. This jump can be seen in the bottom diagram of Figure 6 .

[INSERT FIGURE 6 ABOUT HERE]

\subsection{Sequential credit process}

The bifurcation diagram in Figure $7 \mathrm{~b}$ shows the dynamics of the sequential credit process. The steady state is locally stable for substitution parameters $\nu<0.62$. At $\nu \approx 0.62$ the steady state becomes unstable and a stable 4-cycle emerges. The 4-cycle is produced in a 1:4 resonance bifurcation, a particular type of Hopf bifurcation. The 4-cycle then undergoes a second Hopf bifurcation at $\nu \approx 0.638$ and a 4-piece chaotic attractor emerges (see Figure 7a, top left). The bifurcation diagram also shows that there is coexistence of a 3-cycle and a quasi-periodic attractor for values of the substitution parameter $0.64<\nu<0.66$.

At $\nu<0.6338$ an invariant circle is stable; see Figure 7a, top right. The fluctuations are quasi-periodic and the dynamics follow a limit cycle. The plot shows a phase plot of the dynamics for 10, 000 consecutive periods. Since the attractor is high-dimensional, the plot is a projection of the attractor in a lower dimensional subspace. For this reason the attractor can have self-intersections in the projection, although the attractor itself does not self-intersect.

\section{$(\lambda, \nu)$-diagram}

Figure 7c shows a two-parameter bifurcation diagram. The plot shows that for a fixed substitution parameter $\nu$, the bifurcation scenarios that occur by varying the levels of the price flexibility $\lambda$ are the same for all substitution parameters $0<\nu<0.6$. Although the bifurcations may occur at different parameter values $\lambda_{0}$, the same bifurcation scenario occurs, and a 1-parameter bifurcation diagram with $\lambda$ as the bifurcation parameter will be qualitatively the same for all $0<\nu<0.6$.

\section{[INSERT FIGURE 7 ABOUT HERE]}

\subsection{Comparison of the dynamics of the end-of-period and sequential process}

We now come to a comparison between the dynamics of the credit model with end-ofperiod updating and with sequential updating, respectively. Compare the 2-parameter plots in Figure 6b and Figure 7c. Neither process can be said to be more stable than the other, but if we compare them for all parameter combinations, then we see that they result in different bifurcation scenarios.

For low price elasticities and high price flexibility (low $\nu$, high $\lambda$ ), the end-of-period process produces a stable 12 -cycle while the sequential process produces a stable steady state. Thus for high price flexibilities (high $\lambda$ ) the sequential updating mechanism seems to play a stabilizing role, while for low price flexibilities (low $\lambda$ ) it seems to play a destabilizing role. However, for high price elasticities (high $\nu$ ) both updating mechanisms produce cycles and quasi-periodic behavior. 


\subsection{Influence of the quantity expectations}

We now consider the influence of the quantity expectations on the stability of equilibrium. In Figure 8 we plot three different bifurcation diagrams for three different values of the expectations parameter: $\beta=0.75$ (pessimistic), $\beta=1$ (naive) and $\beta=1.25$ (optimistic). The speed of price adjustment has been kept fixed at $\lambda=0.75$. The diagrams show the same specification of the economy (preferences and endowments). In each diagram the "first" bifurcation occurs at roughly the same value of the substitution parameter: $\nu \approx-0.15$. The only difference between the three diagrams is that for pessimistic expectations $(\beta=0.75$, Figure $8 \mathrm{a})$ we observe more periodic behavior than quasi-periodic behavior, compared to the case with naive or optimistic expectations. The exact bifurcation points depend on the values of the parameters $\nu, \lambda$ and $\beta$, but the structure of the bifurcation scenarios is the same for each case. This can be seen more clearly in Figure 9, showing a 2-parameter bifurcation diagram for $-0.8<\nu<0.3$ and $0<\beta<2$.

Summarizing, whether or not the agents take into account the fact that they are being rationed does not seem to matter for the qualitative features of the dynamics. Therefore we conclude that, in this model of expectations formation, the stability of the steady state equilibrium does not depend on the optimistic or pessimistic expectations, but more on the sequential market structure and on the trading mechanisms.

[INSERT FIGURE 8 ABOUT HERE]

[INSERT FIGURE 9 ABOUT HERE]

\subsection{Conclusions for the credit model}

As mentioned in the introduction, the objective of this paper is to study different versions of the sequential trading model. We are interested in the influence of various market mechanisms and behavioral rules on the qualitative features of the dynamics. Below we make some general observations that follow from the computational analysis thus far. For the credit model with effective demand, we have the following summary of results:

1. The credit mechanism acts as a 'soft' correction mechanism on the fluctuations in the balance of account.

2. The credit mechanism causes agents to make unanticipated debts and claims because they are allowed to enter into credit arrangements, and all transactions are paid by credit transfers.

3. The fluctuations in the credit balance increase with the elasticity of substitution.

4. Attractors for high values of the elasticity of substitution $\nu$ coexist, and the hysteresis effect is a robust phenomenon in the credit model with effective demand; see Figure 6.

5. The models with sequential updating show different bifurcation scenarios than models with end-of-period updating; see Figure 7. The sequential updating of prices plays a destabilizing role in the credit model.

6. The pessimistic and optimistic quantity expectations do not seem to have a qualitative effect on the bifurcation scenarios. The same type of bifurcations seem to occur for different values of the expectations parameter $\beta$; see Fig. 8 and Fig. 9. The 
bifurcations may occur at slightly different parameter values, but the qualitative stability properties are the same.

\section{Cash-in-advance model}

Suppose that agents are not permitted (or do not want) to have a debt during the trade sequence and do not want to hold more money than is strictly necessary to perform transactions. An equilibrium must then satisfy the additional condition that agents' money holdings do not become negative along the sequence. In other words, their trade balance should always remain positive (or non-negative). This requires a positive money stock, which can now be called 'cash', and it defines a 'cash-in-advance equilibrium' (see Clower 1967). The minimum amount of cash an agent needs in order to prevent a trade deficit from occurring is exactly equal to the largest trade deficit that would occur along the sequence if all transactions were to take place in terms of credit transfers between buyers and sellers.

\subsection{The cash-in-advance constraint}

In addition to the budget constraint we now introduce a cash-in-advance constraint, which becomes binding only if the planned consumption at subperiod $(t, i)$ violates the cash position:

$$
p_{i}(t, i) \tilde{z}_{i}^{h}(t, i) \leq M^{h}(t, i) .
$$

This constraint is equivalent to setting the planned trade equal to the minimum

$$
\hat{z}_{i}^{h}(t, i)=\min \left\{\tilde{z}_{i}^{h}(t, i), M^{h}(t, i) / p_{i}(t, i)\right\} .
$$

The cash-in-advance constraint implies that if the money holdings available to agent $h$ at the beginning of subperiod $(t, i)$ suffices only to buy the quantity $M^{h}(t, i) / p_{i}(t, i)$ instead of the optimal amount $\tilde{z}_{i}^{h}(t, i)$, then the minimum amount will be ordered. If however the cash balance is sufficient to buy the optimal quantity (the planned trade is not too expensive) then that amount will be ordered. Note that a cash-in-advance constraint strictly prohibits the occurrence of debts because the cash balance cannot become negative. Note also that the CIA constraint does not enter into the agents' optimization problem directly, but that it is a feasibility constraint that becomes 'active' after the agents have determined their optimal effective demand (desired trades).

In fact the cash-in-advance constraint in combination with the budget constraint ensures that the agents are not running a deficit nor accumulating a surplus. This gives the monetary dynamics a negative feedback mechanism. If prices are too low (high) with respect to the equilibrium levels, then there is an excess demand (supply) for all commodities because the purchasing power of the money balances is too high (low). The general price level will increase (decrease) as all prices adjust to the total money stock $\bar{M}$ in the economy.

\section{Cash-in-advance equilibrium}

In an equilibrium with a positive money stock, the sequence of equilibrium transactions produces a sequence of net revenues for each agent $h=1, \ldots, N$ (a star denotes an equilibrium value): 


$$
R_{i}^{h \star}=-p_{i}^{\star}(t, i) \tilde{z}_{i}^{h \star}(t, i), \quad i=1, \ldots, m
$$

where $R_{i}^{h \star}>0$ denotes the proceeds from sales on market $i$ and $R_{i}^{h \star}<0$ is an expenditure on market $i$. A trade deficit or surplus at subperiod $(t, i)$ is then the sum of net revenues $\sum_{j=1}^{i} R_{j}^{h \star}$. The largest trade deficit that would occur if a negative trade balance would be allowed is given by $\min _{1 \leq i \leq m}\left\{\sum_{j=1}^{i} R_{j}^{h \star}\right\}$. The amount of cash an agent needs in order to prevent this trade deficit from occurring is therefore

$$
M^{h \star}=-\min _{1 \leq i \leq m}\left\{\sum_{j=1}^{i} R_{j}^{h \star}\right\} .
$$

The term $M^{h \star}$ can be interpreted as the equilibrium demand for real balances, which is simply the demand for money. This gives us the necessary condition for defining a cash-in-advance equilibrium.

Definition 1 Cash-in-advance equilibrium (cf. Weddepohl 1996).

A cash-in-advance equilibrium consists of a positive money stock $\bar{M}>0$, a distribution of money holdings $\left\{M^{1 \star}, \ldots, M^{N \star}\right\}$, an allocation $\mathbf{x}^{\star}$ and a price system $\mathbf{p}^{\star}$, such that

1. $\left(\ell^{h \star}, u^{h \star}\right)=(-\infty,+\infty)^{M}$, for all $h, i$,

2. $x_{i}^{h \star}\left(\mathbf{p}^{\star}\right)-w_{i}^{h}=\tilde{z}_{i}^{h}\left(\mathbf{p}^{\star}, \tilde{M}^{h \star}, \ell_{-i}^{h \star}, u_{-i}^{h \star}\right)$ for all $h, i$,

3. $\bar{z}_{i}^{h \star}=\tilde{z}_{i}^{h}\left(\mathbf{p}^{\star}, \tilde{M}^{h \star}, \ell_{-i}^{h \star}, u_{-i}^{h \star}\right)$, for all $h, i$,

4. $\sum_{h} \mathbf{p} \bar{z}^{h}=0$,

5. $M^{h \star}=-\min _{1 \leq i \leq m}\left\{\sum_{j=1}^{i} R_{j}^{h \star}\right\}$, for all $h$,

6. $\sum_{h} M^{h \star}=\bar{M}$.

Conditions (1-4) state that $\left(\mathbf{x}^{\star}, \mathbf{p}^{\star}\right)$ is a Walrasian equilibrium: (1) all rationing constraints are non-binding, (2) the net demand $x_{i}^{h \star}-w_{i}^{h}$ is equal to the effective excess demand, (3) the realized trades after rationing equal the ex-ante effective demands, and (4) is Walras's Law. Condition (5) states that in equilibrium the individual demand for money holdings equals the minimum amount required to prevent a trade deficit, and condition (6) is simply an accounting identity.

Summarizing, the cash-in-advance equilibrium (henceforth CIA equilibrium) has two properties that are important to mention. The first property is that the sequence of equilibrium transactions can be carried out without any agent having a debt along the way since the equilibrium money holdings $M^{h \star}$ are exactly sufficient to prevent any debts from occurring. The second property is that the cash-in-advance constraint is never strictly binding in equilibrium. It can be 'just binding', which means that relaxing it would not lead to a change in the optimum and the agents' optimal consumption decisions would exactly exhaust their available money holdings.

\subsection{Sequential updating of the budget constraint in the cash process}

In the cash-in-advance model we use a different budget-constraint updating mechanism than in the credit model. We cannot simply put the money balance $M^{h}$ on the righthand side of the budget constraint because it does not remain constant along the trade sequence and therefore would not be consistent with a CIA equilibrium. Due to the time-lag between income and consumption (which is due to the sequential structure of the economy) the balance of account $M^{h}$ fluctuates, also in an equilibrium. Because 
of these fluctuations we have to find a more sophisticated way to update the budget constraint, taking into account that the transactions are occurring sequentially and outof-equilibrium. This procedure has to be consistent with a steady state.

What does remain constant in a CIA equilibrium is the change in the cash positions along the equilibrium trading sequence. At every point along the equilibrium sequence the same cash positions are repeated. Also the minimum (and maximum) cash position computed over the entire sequence is the same in every period. Therefore the actual cash balance $M^{h}$ can now be replaced by the minimum cash position computed over the full period. The model contains the following additional concepts:

- The minimum cash position over the previous period, computed at the start of a new period at date $(t, 1)$, is given by

$$
\mu^{h}(t, 1)=\min \left\{M^{h}(t-1,1), \ldots, M^{h}(t-1, m)\right\} .
$$

- The minimum cash position over the previous period, computed at the start of an arbitrary subperiod $(t, i)$, is given by

$$
\mu^{h}(t, i)=\min \left\{M^{h}(t-1, i), \ldots, M^{h}(t-1, m), M^{h}(t, 1), \ldots, M^{h}(t, i-1)\right\} .
$$

In general, we write $\mathbf{p w}^{h}+\mu^{h}$ for the corrected budget constraint, and for the individual excess demands we write

$$
\tilde{\mathbf{z}}^{h}\left(\mathbf{p}, \ell_{-i}^{h}, u_{-i}^{h} ; \mu^{h}\right)=\mathbf{x}^{h}\left(\mathbf{p}, \mathbf{p} \mathbf{w}^{h}+\mu^{h}\right)-\mathbf{w}^{h} .
$$

In a CIA equilibrium $\mu^{h \star}=0$ and $\tilde{\mathbf{z}}^{h}\left(\mathbf{p}, \ell_{-i}^{h}, u_{-i}^{h} ; 0\right)=\mathbf{z}^{h}\left(\mathbf{p}, \ell_{-i}^{h}, u_{-i}^{h}\right)$. This trading plan is consistent in the sense both that agents are not planning to violate their budget constraint and that any positive cash balances are unanticipated (and unintentional).

At subperiod $(t, i)$ the planned trade vector is $\tilde{\mathbf{z}}^{h}\left(\mathbf{p}(t, i),, \ell_{-i}^{h}(t, i), u_{-i}^{h}(t, i) ; \mu^{h}(t, i)\right)$, and it automatically satisfies the budget constraint since all commodities are included in the optimization problem (1). Including $\mu^{h}$ on the right-hand-side of the budget constraint corrects for any positive cash balance that arises due to a trade surplus. Such a positive cash balance arises if an agent first sells some of its endowments and then turns out to be demand-rationed later on. The resulting trade surplus can then be spent immediately on consumption on the next market.

\section{Simulation of the cash model}

Having described the details of the cash model we can again formulate the dynamical system. The sequence of events for the cash model is shown in flowchart 2, now taking into account the box with the cash-in-advance constraint. Figure 10 provides the pseudo code for the market algorithm.

[INSERT FIGURE 10 ABOUT HERE]

\subsection{Timing}

The following steps have to be performed for every agent $h=1, \ldots, N$ during the market visit $i$ in subperiod $(t, i)$, for $i=1, \ldots, m$ and $t=1, \ldots, T$ :

1. Determine the desired transactions $\tilde{z}_{i}^{h}$ by the effective demand rule $\mathbf{E}$ (Eq. 2). 
2. Apply the cash-in-advance constraint to the desired trades to form the buy and sell orders (Eq. 31).

3. Determine the actual transactions $\bar{z}_{i}^{h}$ by the proportional rationing rule $\mathbf{F}$ (Eq. 9).

4. Determine the perceived constraints $\left(\ell_{i}^{h}, u_{i}^{h}\right)$ by the rule $\mathbf{G}$ (Eq. 12).

5. Determine the expected constraints $\left(\tilde{\ell}_{i}^{h}, \tilde{u}_{i}^{h}\right)$ by the rule $\mathbf{H}$ (Eq. 13).

6. Determine the net revenues $R^{h}(t, i)$ from trading on market $i$ (Eq. 14).

7. Update the actual cash balances $M^{h}(t, i+1)$ accordingly (Eq. 15).

8. Update the minimum cash position over the current period (Eq. 35).

9. Update the price $p_{i}(t+1, i)$ for market $i$ by the proportional price adjustment rule DS (Eq. 22).

In Figure 10, in the updating step 8, we have to collect a history of previous cash balances for each individual agent: $\left\{M^{h}(t-1, i+1), \ldots, M^{h}(t-1, m), M^{h}(t, 1), \ldots, M^{h}(t, 1)\right\}$. This is needed in order to calculate the agents' minimum cash positions over the moving horizon period. The sequence $\left\{M^{h}(t-1, i+1), \ldots, M^{h}(t-1, m)\right\}$ comes from the previous period, whereas the sequence $\left\{M^{h}(t, 1), \ldots, M^{h}(t, i)\right\}$ comes from the current period. ${ }^{5}$

\subsection{Example: CES utility}

We again consider an example with $N=3$ agents and $m=3$ commodities. On every market there are two sellers and one buyer (a case of monopsony). The agents all have CES utility functions with preferences and endowments specified as follows:

$$
\begin{aligned}
& U^{a}\left(x^{a}\right)=\left[0.2\left(x_{1}^{a}\right)^{\nu}+0.4\left(x_{2}^{a}\right)^{\nu}+0.4\left(x_{3}^{a}\right)^{\nu}\right]^{1 / \nu}, w^{a}=(50,0,50), M^{a}(0)=100, \\
& U^{b}\left(x^{b}\right)=\left[0.4\left(x_{1}^{b}\right)^{\nu}+0.2\left(x_{2}^{b}\right)^{\nu}+0.4\left(x_{3}^{b}\right)^{\nu}\right]^{1 / \nu}, w^{b}=(50,50,0), M^{b}(0)=100, \\
& U^{c}\left(x^{c}\right)=\left[0.4\left(x_{1}^{c}\right)^{\nu}+0.4\left(x_{2}^{c}\right)^{\nu}+0.2\left(x_{3}^{c}\right)^{\nu}\right]^{1 / \nu}, w^{c}=(0,50,50), M^{c}(0)=100 .
\end{aligned}
$$

The preferences and endowments are such that every agent owns two commodities and strictly prefers one of these two. The agent is indifferent between the commodity that he does not own and the strictly preferred commodity that he does own. This implies that the agent is willing to part with some quantity of the least preferred commodity in exchange for the strictly preferred commodities. With Cobb-Douglas preferences $(\nu=$ 0 ), the planned consumption and the notional excess demands are given by (equilibrium income is $\mathbf{p}^{\star} \mathbf{w}^{h}=100$ )

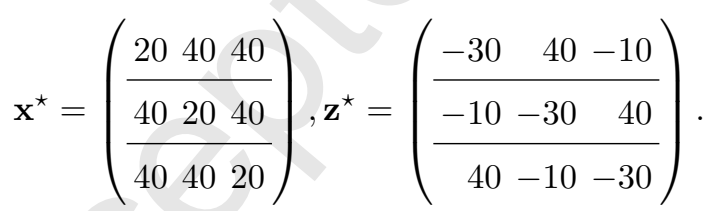

\footnotetext{
$\overline{5}$ It is also possible to simulate a weak form of the cash-in-advance model by leaving out step 2 from the simulations. This removes the 'hard' cash-in-advance constraint, but there is still the correction on the budget constraint by the minimum cash position $\mu^{h}(t, i)$. This would imply that we again allow debts to occur (as in the credit model), but the largest trade deficit is now used as a correction mechanism on the budget constraint. This correction mechanism can be said to act as a 'soft' cash-in-advance constraint since it is driving the dynamics towards a CIA equilibrium without strictly constraining the consumption pattern. The difference with the current model in which we do put the hard restriction on the consumption pattern is rather subtle, and we have not performed a thorough investigation of this matter.
} 


\subsection{Fluctuations in the balance of account in equilibrium}

For the example given above, the equilibrium price system is $\mathbf{p}=(\theta, \theta, \theta), \theta \in \mathbb{R}_{+}$. To every arbitrary positive money stock $\bar{M}>0$ there corresponds a price level $\theta$ that can be determined by the quantity equation $\bar{M}=50 \theta$. The number 50 is coincidental for this choice of preference parameters. In addition, the presence of money makes the indeterminate price levels of the Walrasian equilibrium determinate by fixing the price levels.

The money stock acts as a numeraire, and the price levels adjust to the CIA equilibrium associated with the money stock $\bar{M}$. The initial money holdings of every agent are set to $M^{h}(0)=100$ as an initial condition. This fixes the money stock at $\bar{M}=300$ but given any other value of $\bar{M}$, the money stock will automatically be redistributed among the agent population. The cash distribution $\left\{M^{h \star}\right\}_{h}$ in a CIA equilibrium with a different money stock $\bar{M}$ depends on the proportional change in the money stock: if $\bar{M} \rightarrow a \bar{M}$, then $\left(p_{1}, \ldots, p_{m}\right) \rightarrow\left(a p_{1}, \ldots, a p_{m}\right)$.

For the substitution parameter $\nu=0$ (Cobb-Douglas), the equilibrium cash distribution is given by $M^{1 \star}=60, M^{2 \star}=0, M^{3 \star}=240$. The equilibrium price system associated with the CIA equilibrium is $\mathbf{p}^{\star}=(6,6,6)$ since if prices were $\mathbf{p}^{\star}=(1,1,1)$ then agents' cash requirements are $\sum_{h} M^{h}=50$. Since we have imposed $\bar{M}=300$, the price level is now $\theta=6$. In the CIA equilibrium the sequence of monetary transactions is shown in Table 1. At the start all cash is concentrated with agents 1 and 3. Agent 2 does not need

Table 1

Equilibrium demand for money balances in a CIA equilibrium $(\nu=0)$.

\begin{tabular}{lrrr}
\hline \hline Agent & 1 & 2 & 3 \\
\hline$M^{h}(t, 1)$ & 60 & 0 & 240 Start of market round: initial money holdings. \\
$M^{h}(t, 2)$ & 240 & 60 & 0 Agent 1 receives 180 , agent 2 receives 60 (both from agent 3 ). \\
$M^{h}(t, 3)$ & 0240 & 60 Agent 2 receives 180 , agent 3 receives 60 (both from agent 1$).$ \\
$M^{h}(t, 1)$ & 60 & 0240 Agent 3 receives 180, agent 1 receives 60 (both from agent 2).
\end{tabular}

any cash at the start of market 1 since he is a seller on markets 1 and 2 and a buyer on market 3. Agent 1 needs some cash to be able to buy on market 2, and agent 3 needs cash to buy on market 1 . Agent 3 requires the most cash since he will be buying commodity 1 from both agents 1 and 2 before he can sell commodity 2 to agent 1 and commodity 3 to agent 2 . This reasoning holds from the perspective of starting on market 1 . If we start the equilibrium sequence on market 2, then the cash requirements are rotated cyclically, as shown by the sequence of payments in Table 1. The total amount of cash required for transactions to occur is the row sum 300. The money stock that supports a CIA equilibrium is therefore given by $\bar{M}=300$.

\subsection{Fluctuations in the balance of account out of equilibrium}

We start by analyzing the model from the time series perspective. Below we show three examples of the dynamics:

1. The transition path towards a stable CIA equilibrium $(\nu=-0.1)$. 
2. Fluctuations around an unstable CIA equilibrium for low substitution elasticity $(\nu=0)$.

3. Fluctuations around an unstable CIA equilibrium for high substitution elasticity $(\nu=0.4)$.

The transition path towards a stable CIA equilibrium

In Figure 11 we show time series of the individual cash balances for each agent at the start of each trading round. The variables $M^{1}(t, 1), M^{2}(t, 1), M^{3}(t, 1)$ represent the cash balance of each agent at the start of every period (i.e. the beginning of market 1 ) for 50 consecutive periods $(0<t<50)$. The plots show the entire transition path starting from an initial cash distribution $(100,100,100)$ to the CIA equilibrium: $M^{1 \star}(t, 1)=$ $62, M^{2 \star}(t, 1)=0, M^{3 \star}(t, 1)=238$.

For the substitution parameter $\nu=-0.1$ the CIA equilibrium is asymptotically stable under the specified proportional price dynamics, and each agents' time series converges to values close to the CIA-equilibrium values reported in Table 1 (showing the equilibrium values at $\nu=0)$.

\section{[INSERT FIGURE 11 ABOUT HERE]}

Fluctuations around an unstable CIA equilibrium (low elasticity case)

In Figure 12 we show the typical dynamical behavior for the case of a CIA equilibrium that is unstable. The figure shows phase plots of the cash balances at the start of every market visit for 450 consecutive periods $(50<t<500)$. For Cobb-Douglas utility $(\nu=$ 0 ) the CIA equilibrium is locally unstable. The behavior can be characterized as quasiperiodic since it never repeats in exactly the same pattern.

A more detailed description of the dynamics outside of equilibrium is as follows:

1. Every agent has two trading posts: there are two markets on which an agent is a seller.

2. Agent 1 is sometimes restricted by his cash constraint on market 2 since he is a buyer on market 2 and a seller on markets 1 and 3 . If agent 1 were supply-constrained on market 1 , then he would find himself short of cash and unable to consume on market 2 . The cash constraint therefore becomes binding during his visit to market 2 , just before entering market 3 on which he plans to sell again. At the start of market 3 the cash balance of agent 1 thus reaches the zero level in equilibrium (see plot $(1,3)$ in Fig. 12). At the start of market 1, the cash balance fluctuates around 60 (see plot $(1,1)$ ), and at the start of market 2 it fluctuates around 240 (see plot $(1,2))$. The equilibrium sequence for agent 1 is $(60,240,0)$.

3. Agent 2 wants to sell on markets 1 and 2 and buy on market 3. Therefore a cash constraint becomes binding during his visit to market 3, just before visiting market 1 on which he plans to sell. The cash balance will reach the zero level (in equilibrium) just after having visited market 3 and before market 1 opens for trade (see plot $(2,1)$ in Fig. 12). At the start of market 2 the cash balance fluctuates around 60 (plot $(2,2)$ ), and at the start of market 3 around 240 (plot $(2,3)$ ). The equilibrium sequence for agent 2 is $(0,60,240)$.

4. Agent 3 is a seller on markets 2 and 3 and a buyer on market 1 . He is sometimes rationed by his cash constraint on market 1 . Therefore we see that his cash balance reaches the zero level (in equilibrium) at the beginning of market 2 (see plot $(3,2)$ ). 
At the start of market 3 the cash balance fluctuates around 60 (see plot $(3,3)$ ), and at the start of market 1 around 240 (see plot $(3,1)$ ). The equilibrium sequence for agent 3 is $(240,0,60)$.

A general observation is that for each agent the cash-in-advance constraint becomes binding on the market that is entered just before one of its own trading posts is visited. This means that in equilibrium each agent spends his entire cash holdings just before the agent earns an income by selling some of his endowments again.

[INSERT FIGURE 12 ABOUT HERE]

Fluctuations around an unstable CIA equilibrium (high elasticity case)

In Figure 13 we show what happens for higher values of the substitution parameter $\nu=0.4$ (this corresponds to an elasticity of substitution $\varepsilon=1 /(1-0.4)=1.66$ ). The corresponding equilibrium cash distribution has shifted from $\left\{M^{h \star}(t, 1)\right\}_{h}=(60,0,240)$ to $\left\{M^{h \star}(t, 1)\right\}_{h}=(40.8,0,259.2)$. The phase plots in Figure 13 show that the cash-inadvance constraint becomes binding more often in case of a higher elasticity of substitution. This is due to the higher sensitivity of demand to price fluctuations.

Note that if the cash constraint becomes binding, then the fluctuations in the cash balance remain inside a bounding box in the phase space. This bounded movement seems to be a result of the fact that there is only one buyer per market: the maximum cash position of a seller on a particular market is restricted by the cash constraint of the single buyer on that market. The only way that a seller can obtain a higher income (i.e. reach points that lie outside of the bounding box) is when the buyer is not cash-constrained.

A secondary effect is that the prices bounce back and forth between the price boundaries. This is what we observe in the phase plots in terms of prices in Figure 14. There are upward and downward restrictions on the price growth rates, but not on the absolute levels. These price rigidities are restricting the price-feasibility region: there is a maximum positive growth rate of $10 \%$ and a maximum negative growth rate of $9 \%$. For low values of the elasticity of substitution the prices fluctuate within the bounding region without hitting the price growth restrictions. For higher elasticities of substitution the price dynamics become more volatile, hitting the ceilings and floors and prices are being cut-off.

[INSERT FIGURE 13 ABOUT HERE]

[INSERT FIGURE 14 ABOUT HERE]

\section{Stability analysis}

The stability of the CIA equilibrium depends not only on the elasticity of substitution but also on the price flexibility. To get some insight into the size of the stability regions in the $(\lambda, \nu)$-plane, Figure 15 shows a 2-parameter bifurcation diagram for the elasticity of substitution parameter $0<\nu<0.9$ and the price flexibility parameter $0<\lambda<2$. It illustrates some of the high-order periodic cycles that can occur in the model for different parameter combinations.

[INSERT FIGURE 15 ABOUT HERE] 


\subsection{Conclusions for the cash model}

For the sequential cash-in-advance model we have the following conclusions:

1. The cash-in-advance constraint acts as a 'hard' correction mechanism on fluctuations of the balance of account; see Figure 12. The constraint causes agents to become rationed because they are not allowed to enter into credit arrangements.

2. The variance of the fluctuations of cash balances increases with the elasticity of substitution; see Figure 13.

3. The price rigidities (the ceilings and floors on the price growth rates) can play an important role in restricting the dynamics, as can be seen in Figure 14. The erratic dynamics are likely to be caused by a border-collision between the trajectory and one of the price boundaries, causing quasi-periodic behavior that can be called 'chaos in a box'.

4. The use of effective demand functions in the cash-in-advance model does not lead to more stable dynamics than those in the notional demand models. The spill-over effects from quantity rationing do not always work as a stabilizing mechanism. Even if agents take into account that they are being rationed by incorporating the quantity constraints into their decisions, this does not reduce the potential for fluctuating dynamics.

5. The sequential updating mechanism plays a stabilizing role for low values of the price flexibility parameter (low $\lambda$ ); see Figure 15.

\section{Conclusions}

We have described in detail a model with disequilibrium trade and various market mechanisms. There is quantity rationing to clear the market, and transactions take place sequentially. Agents' balances of account are tracked over time by keeping account of the debts and claims they make out of equilibrium.

We have used the cash-in-advance (Clower-) constraint that leads to an alternative equilibrium concept, namely that the sequence of payments along the period remains the same and cash has to be used for all transactions. The CIA equilibrium retains all the properties of a general equilibrium (i.e., it is a Walrasian equilibrium) except that it is no longer indeterminate since there is a positive money stock that determines the level of prices.

According to Magill and Quinzii (p. 488) a satisfactory modelling of money requires an open-ended future. Trade should take place in a sequence economy in which the imperfections in the trading opportunities of the agents play a role. Although the model presented here has a finite planning horizon instead of an infinite horizon, nonetheless the future is open-ended because the agents are myopic: they plan only one period ahead. Due to trade at disequilibrium prices and the spill-over effects from quantity rationing, agents have to revise their trading plans subject to new information arriving during the trading process. Such a moving-horizon time-structure results in a genuinely dynamic model of a monetary exchange economy with trade out of equilibrium.

In the credit model all transactions are paid by credit transfers, and agents are allowed to have debts or claims on wealth. The credit mechanism acts as a 'soft' correction mechanism on the fluctuations in the balance of account by correcting for the accumulated 
trade deficits or surpluses, but it also causes the agents to accumulate unanticipated debts and claims because they are not restricted in making such credit arrangements. The trade deficits or surpluses then have to be repaid during the next sequence of trades.

The first result is that the introduction of the correction mechanism does not preclude cyclical behavior. If debts are allowed this may lead to stable cycles around an equilibrium. The credit model shows large fluctuations in the credit balances before it converges, which implies that agents accumulate debts along the transition path. If the process does not converge to a steady state, then agents continue to accumulate debts and claims over time despite the corrections on their budget constraints.

The second result is that the cash-in-advance constraint acts as a 'hard' correction mechanism on fluctuations in the balance of account because the agents are not allowed to enter into any credit arrangements at all. In combination with the corrections on the budget constraint, the cash-in-advance constraint acts as a negative feedback mechanism, driving the economy back towards an equilibrium if the disequilibrium becomes too large, but due to the fact that agents are not allowed to accumulate any debts along the transition path, the cash-in-advance constraint also causes the agents to become demandrationed. The CIA constraint does not help to dampen the amplitude of the fluctuations or to prevent cycles from occurring because the correction mechanism may overshoot. When this occurs there are large swings in prices that will directly influence the cash balances as well since the transactions have to be paid at fluctuating price levels.

The cash-in-advance constraint becomes binding more often in case of a higher elasticity of substitution parameter $\nu$. This is due to a higher sensitivity of demand to price fluctuations. These fluctuations are then exacerbated by the cash-in-advance constraint rather than dampened.

If the cash-in-advance process converges to a neighborhood of the cash-in-advance equilibrium, then the process shows small fluctuations around the steady state before it converges, and the convergence takes place without the occurrence of debts and claims along the transition path. However, for large values of the elasticity of substitution parameter $\nu$, the process may still produce periodic or quasi-periodic behavior.

Two rather different types of restrictions play a role if the elasticity of substitution is increased: there is the cash-in-advance constraint that becomes binding more often, and there are the price rigidities (the ceilings and floors on the price growth rates) that become more restrictive. These restrictions are strongly related: if the price fluctuations become more erratic (by an increased price-elasticity of the demand for commodities), then also the income of the agents will fluctuate more violently, as will the cash balances. The fluctuations in the cash balances in turn affect the agents' demand and supply decisions, causing fluctuations in the excess demands. These excess demand fluctuations then feed back into the dynamics of the price fluctuations.

In conclusion, for the dynamics to be stable it seems necessary that the correction mechanism is not updating too fast since this may exacerbate fluctuations of the balance of account. This hints at a more general conjecture that the market mechanisms and the market structure are perhaps of greater importance than whether or not the agents are in fact using optimal trading strategies that take into account all of the relevant market signals. The main message of our simulation exercises is that even if agents take all of these relevant market signals into account and update their budget constraints and expectations accordingly, the occurrence of erratic dynamics cannot be dismissed by introducing more sophisticated correction mechanisms. 


\subsection{Final remarks}

We must acknowledge that the model is a simple trading model without a production sector or a financial sector. Furthermore, all transactions are mediated through a central exchange. The model can be extended in various directions:

1. Endogenization of the expectations parameter $\beta$.

2. Extending the model to include debt defaults.

3. Randomization of the market visiting orders.

4. Investigation of a large-scale, parallel trading model with asynchronous sequential trade.

5. Comparison of the asynchronous (sequential) trading model with a synchronous (simultaneous) trading model.

The first three items are relatively minor extensions to the current model. The endogenization of the expectations parameter $\beta$ would allow the agents to switch endogenously from being optimistic to being pessimistic about their future trading opportunities and would introduce learning into the model. However, since we have already shown above that the stability properties do not rely on the value of the expectations parameter, this extension might not result in any new knowledge.

The extension to include debt defaults were to bring in new elements, such as contagion effects. In the current model the agents can always borrow as much as they want, even though they do not borrow more then they subjectively expect to be able to repay in the near future. The current model also includes forced debt repayments. If we would introduce credit restrictions and the possibility of default, they could very well affect the dynamics of the credit model.

The randomization of the market visiting orders can be used to investigate whether the stability depends on particular trading orders. Recent ACE literature has begun to address this issue by studying the effects of different agent activation regimes (e.g., Axtell 2000, 2005), and the organization of trading networks (e.g., Wilhite 2001).

The last two items are more fundamental. In the introduction to Section 2 it was noted that the trading order used here is a very special case of a more general time structure. An important extension would consider the case with more goods traded per trading post.

An interesting case is the model with asynchronous, sequential trade in which all markets are open all the time. Agents trade in parallel on different markets and occasionally meet each other. Ideally, one would want to study the full spectrum of market specifications, starting from the case with totally incomplete markets (only one market is open and a single good can be traded per trading post) to the case with complete markets where all markets are open.

The model could be further generalised by allowing the agents to have heterogeneous planning horizons. Both extensions will require further computational experiments with larger agent populations. Finally, the question of whether agents can chose when and with whom to trade is also of importance and deserves further attention in future models. 


\section{Acknowledgement}

The research for this paper was done at the Center for Nonlinear Dynamics in Economics and Finance (CeNDEF), University of Amsterdam. I thank Claus Weddepohl, Cars Hommes, Cees Diks, Jan Tuinstra and Florian Wagener for helpful discussions and comments. I also thank the editor Barkley Rosser and two anonymous referees for their comments and careful reading of the manuscript. Earlier versions of this paper have been presented at various stages of development; at the SCE 2004 conference in Amsterdam, WEHIA 2005 in Essex, and Complexity 2006 in Aix-en-Provence. I thank the participants at these meetings for their comments. The usual disclaimer applies.

\section{Appendix A. Technical details: the hysteresis effect}

In this appendix we give technical details on the hysteresis effect that is observed in the credit model.

Consider a 1-dimensional parameter family of functions $f_{a}(x), f_{a}: \mathbb{R} \rightarrow \mathbb{R}$ and $a \in \mathbb{R}$. Let $x=0$ be a steady state and the parameter ' $a$ ' is a bifurcation parameter. The generic bifurcation scenario that can be used to illustrate the hysteresis effect is the subcritical pitchfork bifurcation as shown in Figure 16.

[INSERT FIGURE 16 ABOUT HERE]

A steady state is locally stable for $a<0$. At $a=0$ two backward bending branches of two unstable fixed points bifurcate from the steady state. These branches are first unstable (dotted line) and then become stable at $a=r$ (solid line). For parameter values $r<a<0$ there exist 5 fixed points: the original stable steady state, a pair of stable fixed points and a pair of unstable fixed points. Which of the stable fixed points is reached depends on the initial condition, in particular whether the initial condition is above or below one of the unstable branches.

Suppose we start from left-to-right and slowly increase the parameter $a$ towards $a=0$. The steady state remains locally stable until it loses stability at $a=0$. For $a>0$ the steady state continues to exist, but since it is locally unstable any small perturbation will cause the state to jump to one of the stable branches above or below the steady state (the jump is indicated by the arrow marked ' 1 '). If $a$ is increased even further, the state will diverge along one of the stable branches since both of these branches are locally stable. If we now start to decrease $a$ from $a>0$ to $a=0$ the state will remain on the stable branch without jumping back immediately at $a=0$. We have to decrease $a$ until $a=r$ for the system to jump back to the original steady state (this jump is indicated by the arrow marked ' 2 '). This lack of reversibility when a parameter is changed and then changed back to its original value is the hysteresis effect.

The bifurcation at $a=r$ when $a$ is increased from left to right, in which the four fixed points (the stable pair and the unstable pair) appear 'out of the clear blue sky', is a saddle-node bifurcation. When $a$ is decreased from right to left, the four fixed points suddenly disappear as the stable and unstable pairs collide and two saddle-sink pairs appear. The bifurcation at $a=0$ when $a$ is increased from left-to-right is a subcritical pitchfork bifurcation (also called a 'hard' bifurcation because of the sudden jump). 


\section{References}

Axtell, R. L., 2000. Effects of interaction topology and activation regime in several multiagent systems. In: Moss, S., Davidsson, P. (Eds.), MABS 2000: Multi-agent-based simulation. Vol. 1979 of Lecture Notes in Computer Science. Berlin: Springer, pp. $33-48$.

Axtell, R. L., 2005. The complexity of exchange. The Economic Journal 115, 193-210.

Benassy, J.-P., 1975. Neo-Keynesian disequilibrium theory in a monetary economy. Review of Economic studies 42, 503-523.

Clower, R. W., 1965. The Keynesian counter-revolution: A theoretical appraisal. In: Hahn, F. H., Brechling, F. P. R. (Eds.), The Theory of Interest. New York: Macmillan, pp. 103-125.

Clower, R. W., 1967. A reconsideration of the microfoundations of monetary theory. Western Economic Journal 6, 1-9.

Clower, R. W., Leijonhufvud, A., 1975. The coordination of economic activities: A Keynesian perspective. American Economic Review 65, 182-188.

Goeree, J. K., Hommes, C., Weddepohl, C., 1997. Stability and complex dynamics in a discrete tâtonnement model. Journal of Economic Behavior and Organization 33, 395-410.

Green, J., 1980. On the theory of effective demand. Economic Journal 90, 341-353.

Hansson, B. A., 1982. The Stockholm School and the development of dynamic method. London: Croom Helm.

Hayek, F. A., 1928. Das intertemporale gleichwichtssystem der preise und die bewegungen des 'geldwertes'. Weltwirtschaftliches Archiv 28, 37-76, [English translation; 1984. Intertemporal price equilibrium movements in the value of money, In: Kirzner, I.M. (Ed.). Classics in Austrian Economics III: the Age of Mises and Hayek. London: William Pickering.].

Hicks, J. R., 1939. Value and Capital: An Inquiry into some Fundamental Principles of Economic Theory. New York: Oxford University Press, Rpt. Oxford: Clarendon Press, 1974.

van der Hoog, S., 2005. Microeconomic Disequilibrium Dynamics. Amsterdam: Thela Thesis, available online: http://dare.uva.nl/record/150442.

Kiyotaki, N., Wright, R., 1989. On money as a medium of exchange. Journal of Political Economy 97, 927-954.

Leijonhufvud, A., 1968. On Keynesian Economics and the Economics of Keynes. New York: Oxford University Press.

Lindahl, E., 1939. The dynamic approach to economic theory. New York: A.M. Kelley, 1967.

Magill, M., Quinzii, M., 1996. Theory of Incomplete Markets. Vol. 1. Cambridge, MA: MIT Press.

Saari, D. G., 1985. Iterative price mechanisms. Econometrica 53, 1117-1131.

Scarf, H., 1960. Some examples of global instability of the competitive equilibrium. International Economic Review 1, 157-172.

Shubik, M., 1999. The Theory of Money and Financial Institutions. Vol. 1. Boston: MIT Press.

Stiglitz, J., 2003. The Roaring Nineties. London: Penguin Books. 
Tuinstra, J., 2000. Price Dynamics in Equilibrium Models. Dordrecht: Kluwer Academic Publishers.

Weddepohl, C., 1995. A cautious price adjustment mechanism: chaotic behavior. Journal of Economic Behavior and Organization 27, 293-300.

Weddepohl, C., 1996. A simulation study of disequilibrium price dynamics. In: Barnett, W., Gandolfo, G., Hillinger, C. (Eds.), Dynamic Disequilibrium Modelling. Cambridge: Cambridge University Press, pp. 421-443.

Weinrich, G., 1988. On the foundations of stochastic non-price rationing and the adjustment of prices. Rivista di mathematica per le scienze economiche e sociali 11, 107-131.

Wilhite, A., 2001. Bilateral trade and 'small-world' networks. Computational Economics $18,49-64$.

Zappia, C., 2001. Equilibrium and disequilibrium dynamics in the 1930s. Journal of the History of Economic Thought 23, 55-75. 
Table 1

Model variations according to the categorization of market mechanisms.

\begin{tabular}{|l|l|l|}
\hline & Credit exchange process & Cash exchange process \\
\hline Sequential & Model 1: & Model 2: \\
updating of prices & - effective demand & - effective demand \\
and budget constraints & - sequential updating & - sequential updating \\
& - credit exchange & - cash exchange \\
\hline End-of-period & Model 3: & Model 4: \\
updating of prices & - effective demand & - effective demand \\
and budget constraints & - end-of-period updating & - end-of-period updating \\
& - credit exchange & - cash exchange \\
\hline
\end{tabular}

Table 2

Model variables.

\begin{tabular}{|c|c|}
\hline$(t, i)$ & period $t$, subperiod $i$; the market visit for trading post $i$ \\
\hline$((t, 1), \ldots,(t, m))$ & complete trading round, one iteration \\
\hline$p_{i}(t, i)$ & price on market $i$ in subperiod $(t, i)$ \\
\hline $\mathbf{p}(t, i)$ & price vector in subperiod $(t, i) ; \mathbf{p}(t, i)=\left(p_{1}(t, i), \ldots, p_{m}(t, i)\right)$ \\
\hline$c_{i}^{h}$ & desired consumption by agent $h$ of good $i$ \\
\hline$w_{i}^{h}$ & endowment of agent $h$ of good $i$ \\
\hline$\tilde{z}_{i}^{h}$ & effective excess demand of agent $h$ for good $i$ \\
\hline $\bar{z}_{i}^{h}$ & actual trade of agent $h$ for good $i$ \\
\hline$\hat{z}_{i}^{h}$ & actual trade ex-post CIA constraint; $\hat{z}_{i}^{h}(t, i)=\min \left\{\tilde{z}_{i}^{h}(t, i), M^{h}(t, i) / p_{i}(t, i)\right\}$ \\
\hline$d_{i}^{h}$ & net demand by agent $h$ for $\operatorname{good} i ; d_{i}^{h}=\max \left\{0, \tilde{z}_{i}^{h}\right\}$ \\
\hline$s_{i}^{h}$ & net supply by agent $h$ for $\operatorname{good} i ; s_{i}^{h}=\min \left\{0, \tilde{z}_{i}^{h}\right\}$ \\
\hline$D_{i}$ & aggregate market demand for good $i ; D_{i}=\sum_{h} d_{i}^{h}$ \\
\hline$S_{i}$ & aggregate market supply for good $i ; S_{i}=-\sum_{h} s_{i}^{h}$ \\
\hline$\ell_{i}^{h}$ & realized supply constraint, set by the rationing mechanism \\
\hline$u_{i}^{h}$ & realized demand constraint, set by the rationing mechanism \\
\hline$\tilde{\ell}_{i}^{h}$ & expected supply constraint, subjective for the agents \\
\hline$\tilde{u}_{i}^{h}$ & expected demand constraint, subjective for the agents \\
\hline$M^{h}(t, i)$ & money holdings of agent $h$ at the beginning of subperiod $(t, i)$ \\
\hline$R^{h}(t, i)$ & net revenues measured at the end of subperiod $(t, i)$ \\
\hline$\Delta M^{h}(t, i)$ & moving horizon net revenues, measured at the beginning of subperiod $(t, i)$ \\
\hline$\tilde{M}_{\text {(sequential) }}^{h}(t, i)$ & money holdings corrected for unanticipated debts and claims (in the sequential version) \\
\hline \multicolumn{2}{|c|}{$\tilde{M}_{\text {(end-of-period) }}^{h}(t, i)$ money holdings corrected for unanticipated debts and claims (in the end-of-period version) } \\
\hline$\mu^{h}(t, 1)$ & minimum cash holdings over the previous period, measured at $(t, 1)$ \\
\hline$\mu^{h}(t, i)$ & minimum cash holdings over a moving time horizon, measured at $(t, i)$ \\
\hline
\end{tabular}


Table 3

Model parameters.

\begin{tabular}{lll}
\hline \hline \multicolumn{2}{l}{ label range } & description \\
\hline$\nu$ & $(-\infty, 1)$ & CES parameter \\
$\beta$ & {$[0,2]$} & expectations parameter \\
$\lambda$ & {$[0,2]$} & price flexibility parameter \\
$r^{+}$ & {$[0,1]$} & upward rigidity on price growth rates \\
$r^{-}$ & {$[0,1]$} & downward rigidity on price growth rates \\
$\pi^{+}$ & {$\left[1,1+r^{+}\right]$maximum positive growth factor } \\
$\pi^{-}$ & {$\left[1-r^{-}, 1\right]$ maximum negative growth factor } \\
\hline \hline
\end{tabular}

Table 4

Moving Horizon Optimization.

\begin{tabular}{r|r}
\hline \hline date & planned consumption for agent $h$ \\
\hline$(t, 1)$ & $c_{1}^{h}(t, 1) c_{2}^{h}(t, 1) c_{3}^{h}(t, 1)$ \\
$(t, 2)$ & $c_{2}^{h}(t, 2) c_{3}^{h}(t, 2) c_{1}^{h}(t, 2)$ \\
$(t, 3)$ & $c_{3}^{h}(t, 3) c_{1}^{h}(t, 3) c_{2}^{h}(t, 3)$ \\
\hline \hline
\end{tabular}




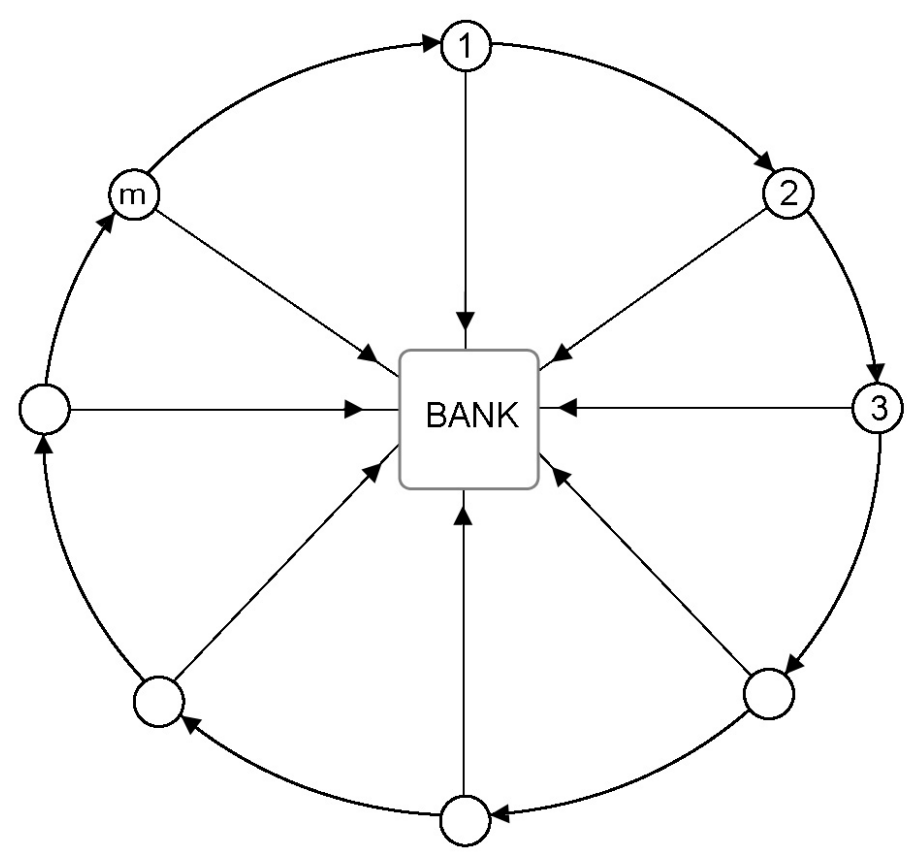

Fig. 1. The sequential 'trading posts'-interpretation. 


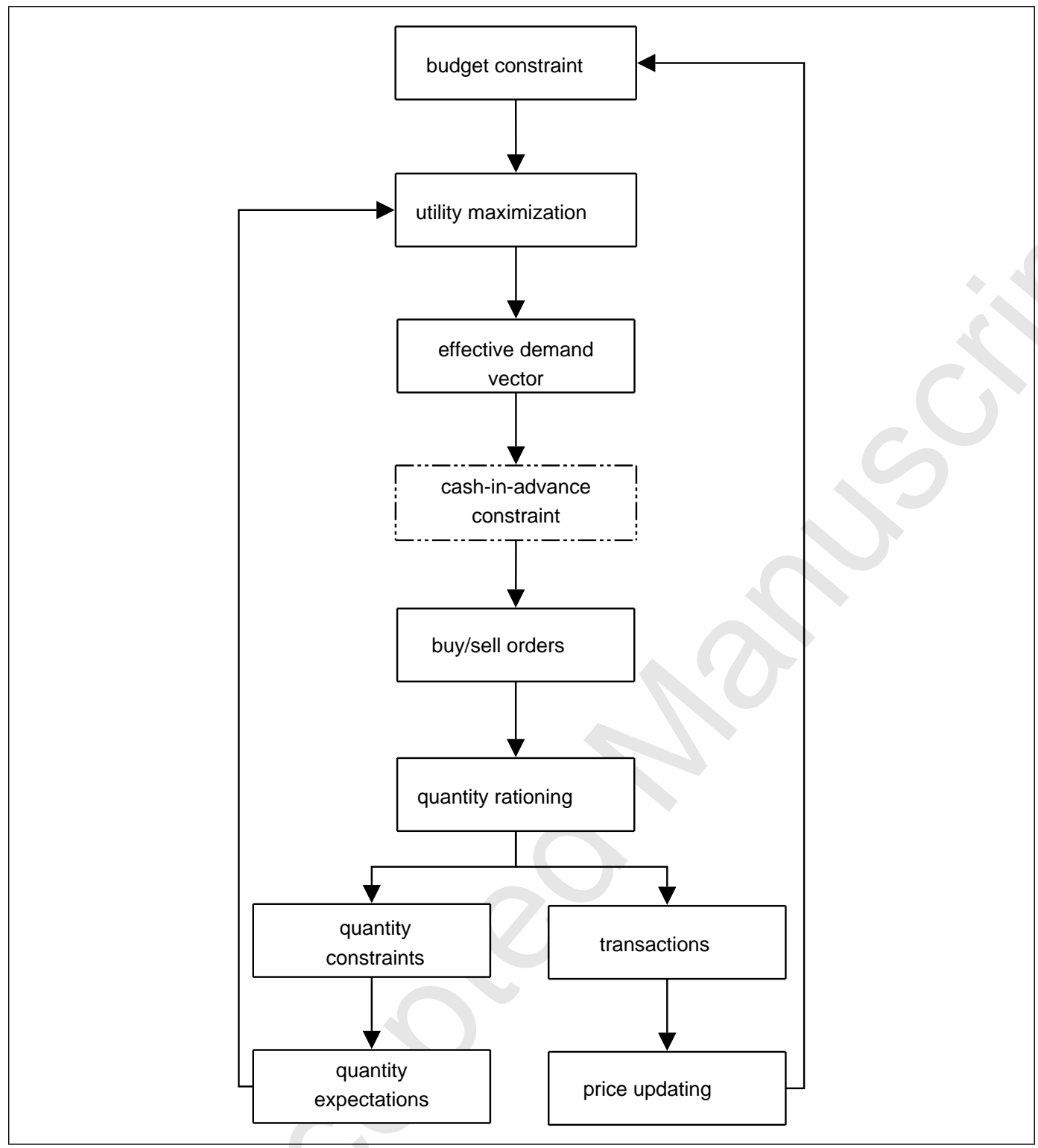

Fig. 2. Flow diagram of market events in the sequential credit process with quantity expectations and effective demand (for the credit model, we ignore the box with the cash-in-advance constraint). The diagram shows the buy and sell orders that agents send to the market and the quantity rationing signals that are sent back to them. The cycle refers to a single agent during a single market visit. It is repeated for each market $i=1, \ldots, m$, after which the next period begins. 


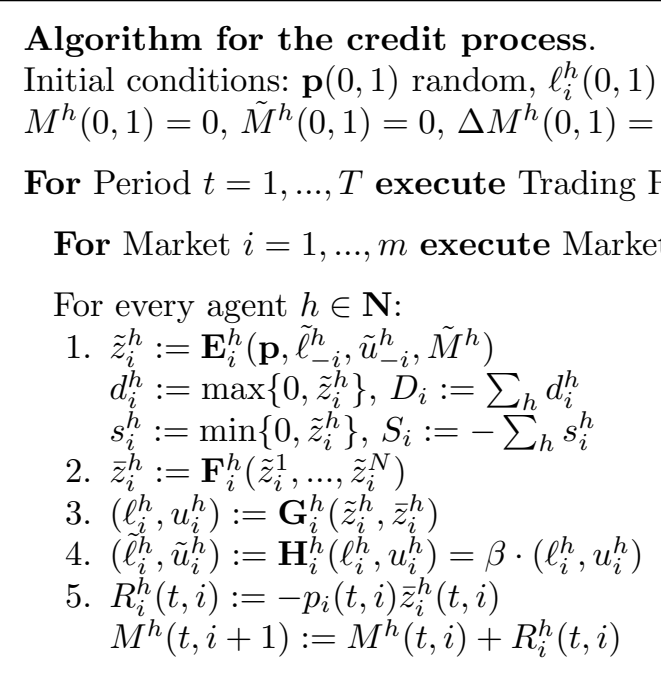

\section{Sequential updating procedure:}

For every agent $h \in \mathbf{N}$ :

6a. $\Delta M^{h}(t, i):=M^{h}(t, i)-M^{h}(t-1, i)$

$$
\tilde{M}^{h}(t, i+1):=M^{h}(t, 1)+\Delta M^{h}(t, i)
$$

7a. $p_{i}(t, i+1):=\max \left\{\left(1-r^{-}\right) p_{i}(t, i), \min \left\{p_{i}(t, i)\left(\frac{D_{i}(t, i)}{S_{i}(t, i)}\right)^{\lambda},\left(1+r^{+}\right) p_{i}(t, i)\right\}\right\}$

8a. $\mathbf{p}:=m \cdot\left(\mathbf{p} / \sum_{j} p_{j}\right)$ (price normalization)

$M^{h}(t, i+1):=m \cdot\left(M^{h}(t, i+1) / \sum_{j} p_{j}\right)$ (credit balance normalization)

\section{end of market visit}

\section{End-of-period updating procedure:}

For every agent $h \in \mathbf{N}$ :

6b. $\tilde{M}^{h}(t+1,1):=M^{h}(t+1,1)$

7b. $p_{i}(t+1,1):=\max \left\{\left(1-r^{-}\right) p_{i}(t, 1), \min \left\{p_{i}(t, 1)\left(\frac{D_{i}(t, i)}{S_{i}(t, i)}\right)^{\lambda},\left(1+r^{+}\right) p_{i}(t, 1)\right\}\right\}$

$p_{i}(t+1, j):=p_{i}(t+1,1)$ for all $j=2, \ldots, m$.

8b. $\mathbf{p}(t+1,1):=m \cdot \mathbf{p}(t+1,1) / \sum_{j} p_{j}(t+1,1)$ (price normalization)

$M^{h}(t+1,1):=m \cdot\left(M^{h}(t+1,1) / \sum_{j} p_{j}(t+1,1)\right)$

(credit balance normalization)

end of period

end of simulation.

Fig. 3. Pseudo code algorithm for the credit process with sequential and end-of-period updating respectively. The time-index $(t, i)$ has been suppressed in steps 1-4 for clarity of exposition. 

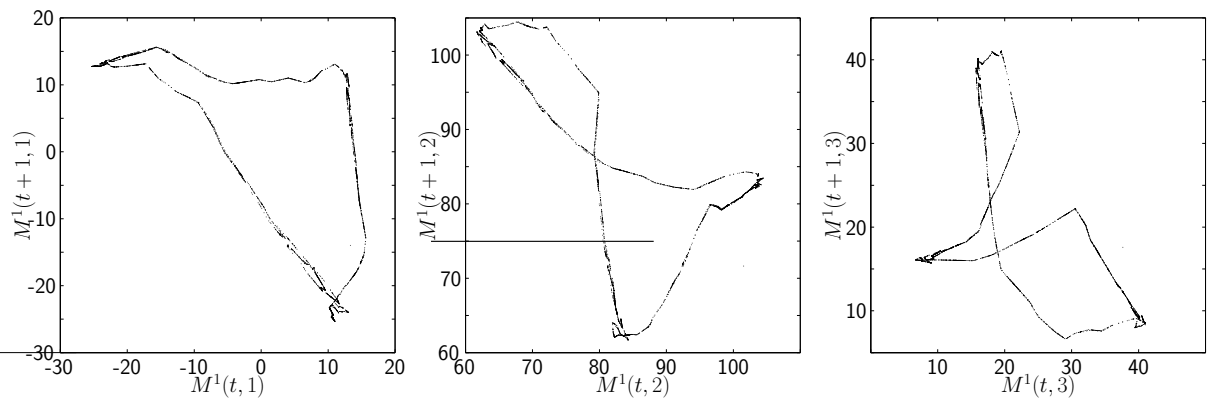

Fig. 4. Model 1. Credit process with end-of-period updating. Parameters: $\nu=0.52, \lambda=0.75, \beta=1$. Phase plots of the individual credit balance for agent 1 at the start of market 1,2 and $3:\left(M^{1}(t, 1), M^{1}(t+1,1)\right)$; $\left(M^{1}(t, 2), M^{1}(t+1,2)\right)$ and $\left(M^{1}(t, 3), M^{1}(t+1,3)\right)$. The credit balance fluctuates around the equilibrium values.

Price level $p_{1}(t, 1)$
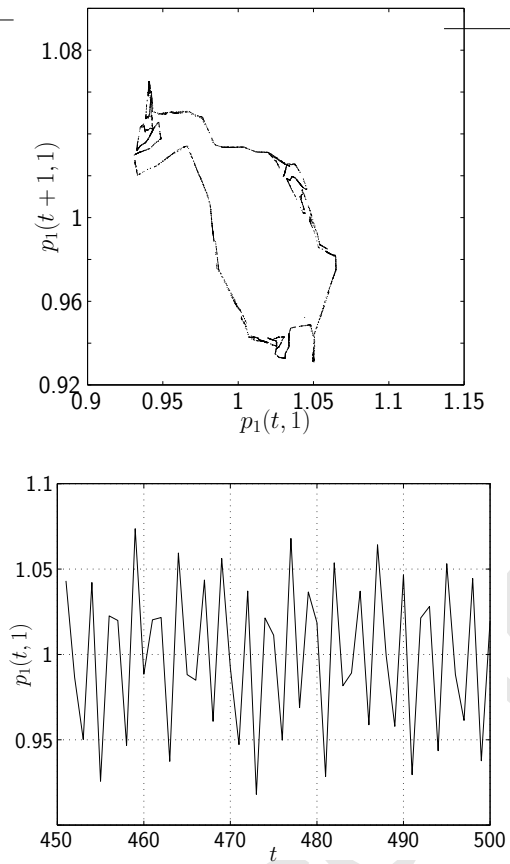

Excess demand $z_{1}(t, 1)$
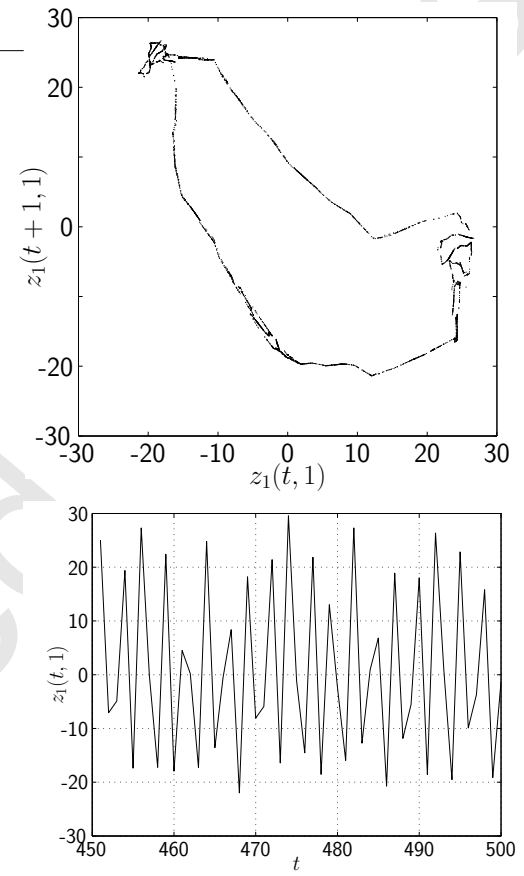

Fig. 5. Model 1. Credit process with end-of-period updating. Parameters: $\nu=0.52, \lambda=0.75, \beta=1$. Phase plots and time series of the price level $p_{1}(t, 1)$ and the total excess demand $z_{1}(t, 1)$, for 50 consecutive periods $(450<t<500)$. 


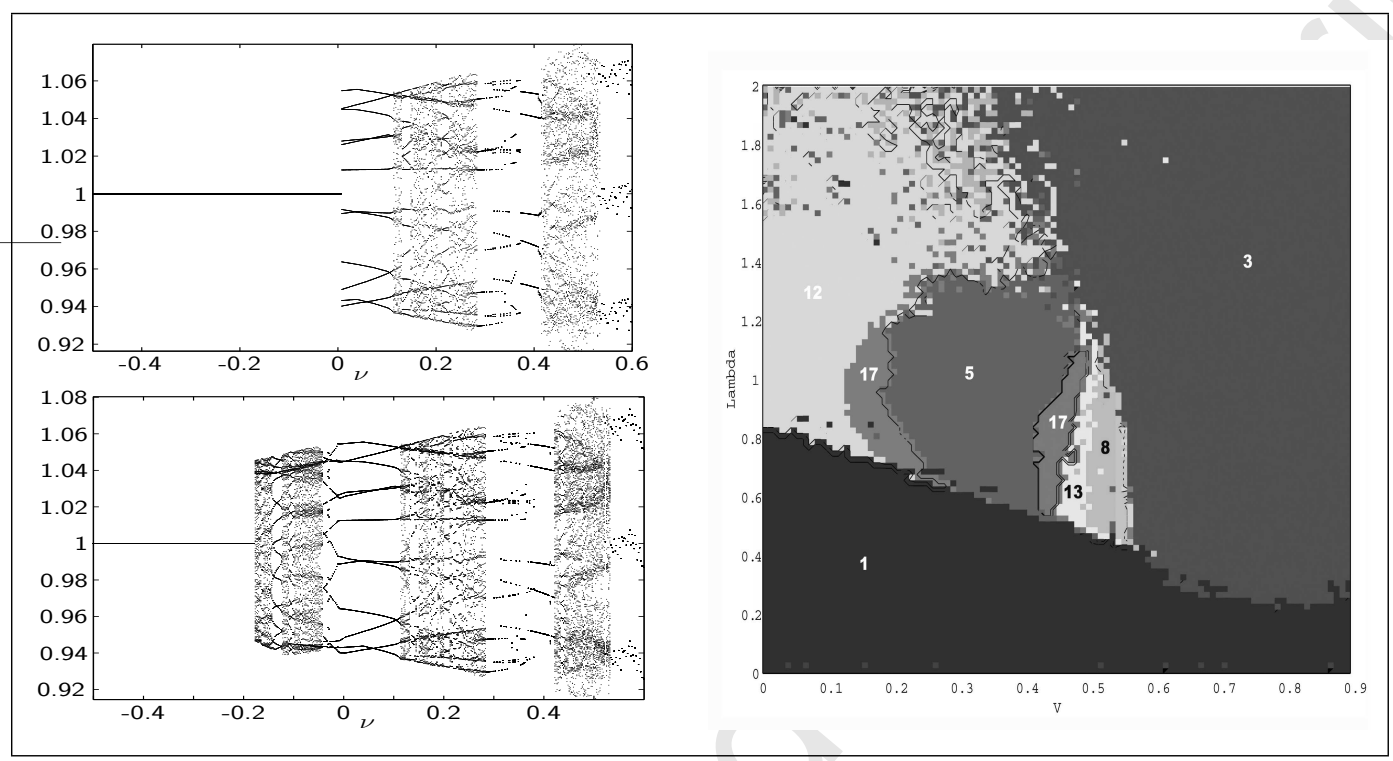

Fig. 6. Model 1. Credit process with end-of-period updating. (a) 1-parameter bifurcation diagram in terms of the price $p_{1}(t, 1)$ produced from "left-to-right", (b) 1-parameter bifurcation diagram produced from "right-to-left". Parameters: $\lambda=1,-0.5<\nu<0.6$. (c) 2-parameter bifurcation diagram produced from "right-to-left" in the $(\lambda, \nu)$-plane, $\beta=1,0<\lambda<2,0<\nu<0.9$. 


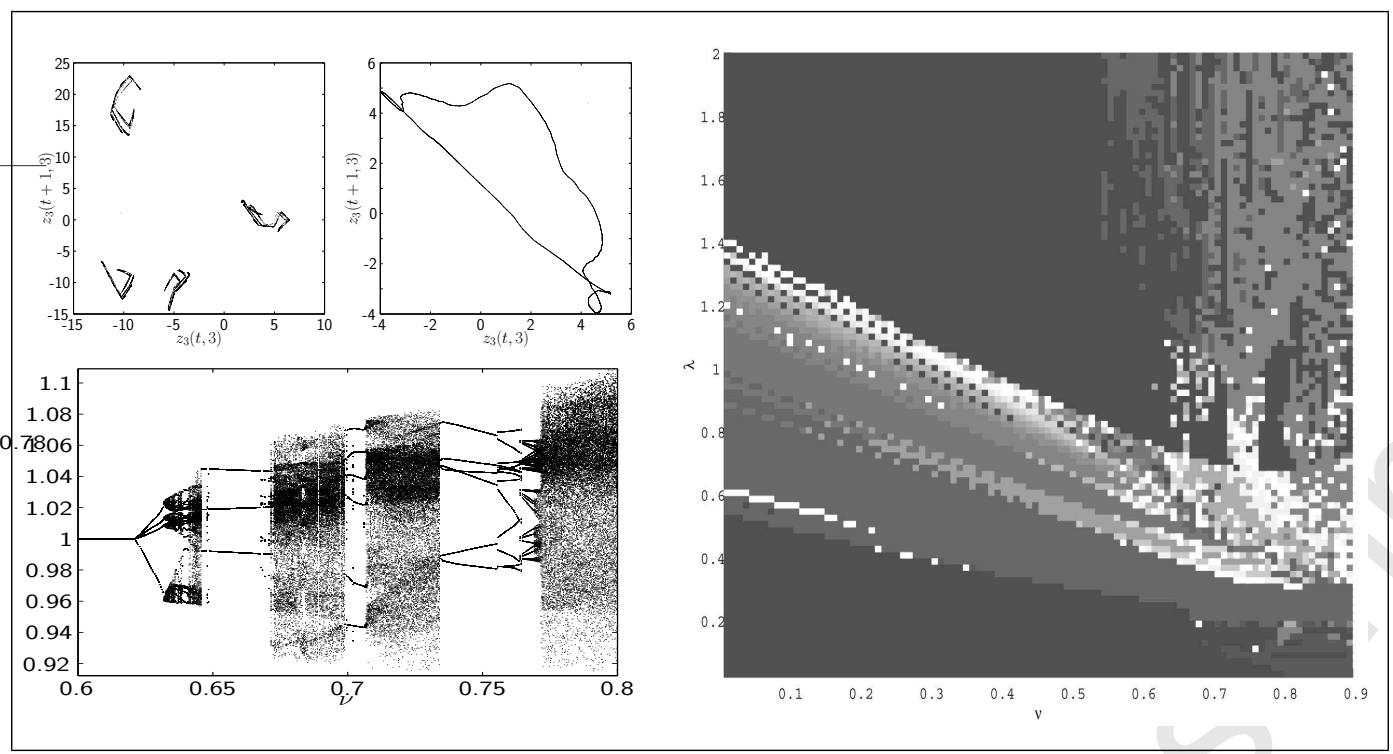

Fig. 7. Model 2. Credit process with sequential updating. (a) Phase plots in excess demand $z_{3}$. Parameters: $\lambda=1, \beta=1, \nu=0.6338$ and $\nu=0.638$. (b) 1-parameter bifurcation diagram in terms of the price $p_{1}$ produced from "left-to-right". Parameters: $\lambda=0.5,0.6<\nu<0.8$. (c) 2-parameter bifurcation diagram in the $(\lambda, \nu)$-plane. Parameters: $\beta=1,0<\lambda<2,0<\nu<0.9$. 


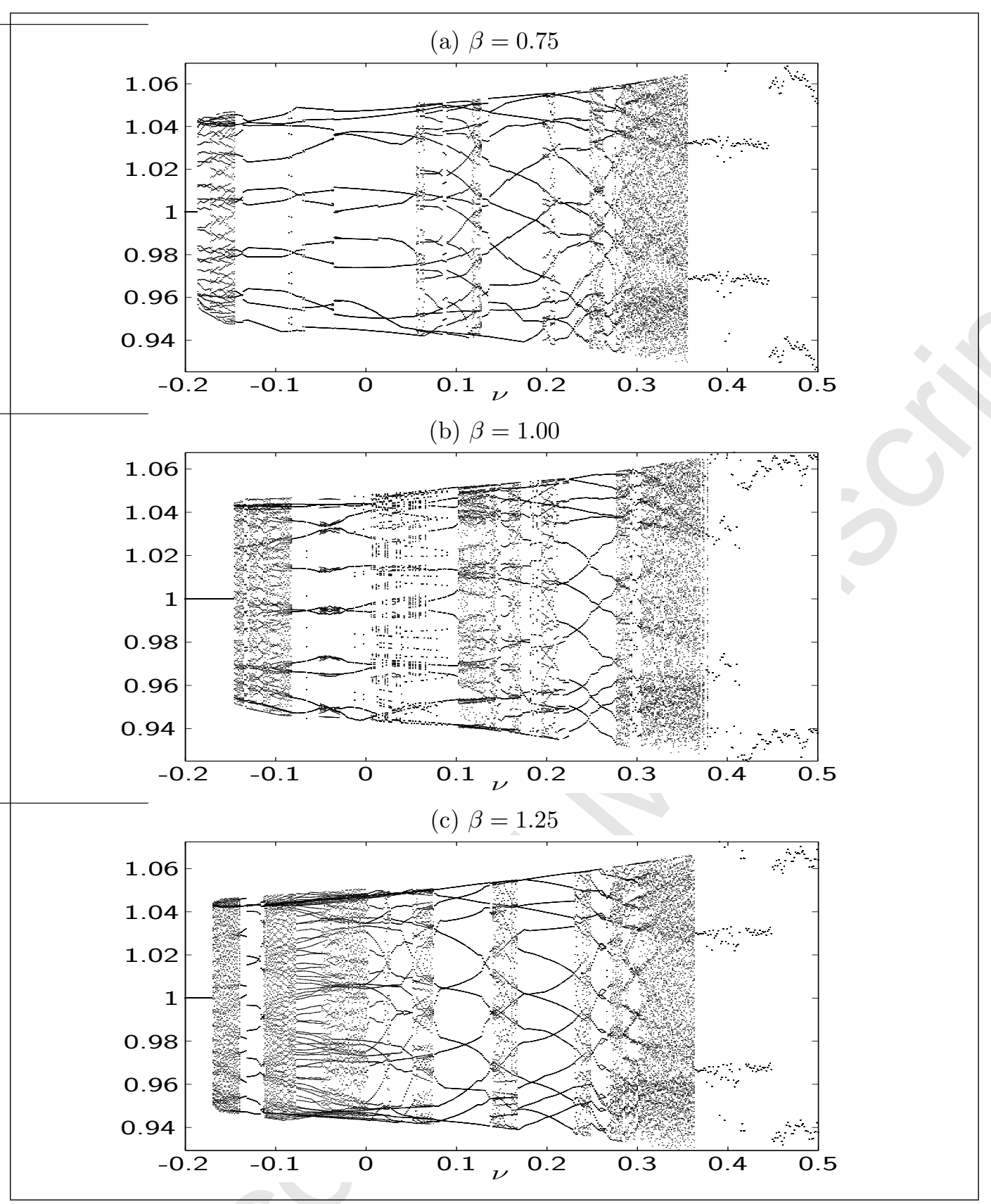

Fig. 8. Model 1. Credit process with end-of-period updating. 1-Parameter bifurcation diagrams for different values of the expectations parameter: (a) $\beta=0.75$ (b) $\beta=1$ (c) $\beta=1.25$. The first bifurcation occurs at approximately the same parameter value: $\nu \approx-0.15$. Parameters: $\lambda=0.75,-0.2<\nu<0.5$, $T=200,20$ pre-iterations. Vertical axis: price level $p_{1}(t, 1)$. 


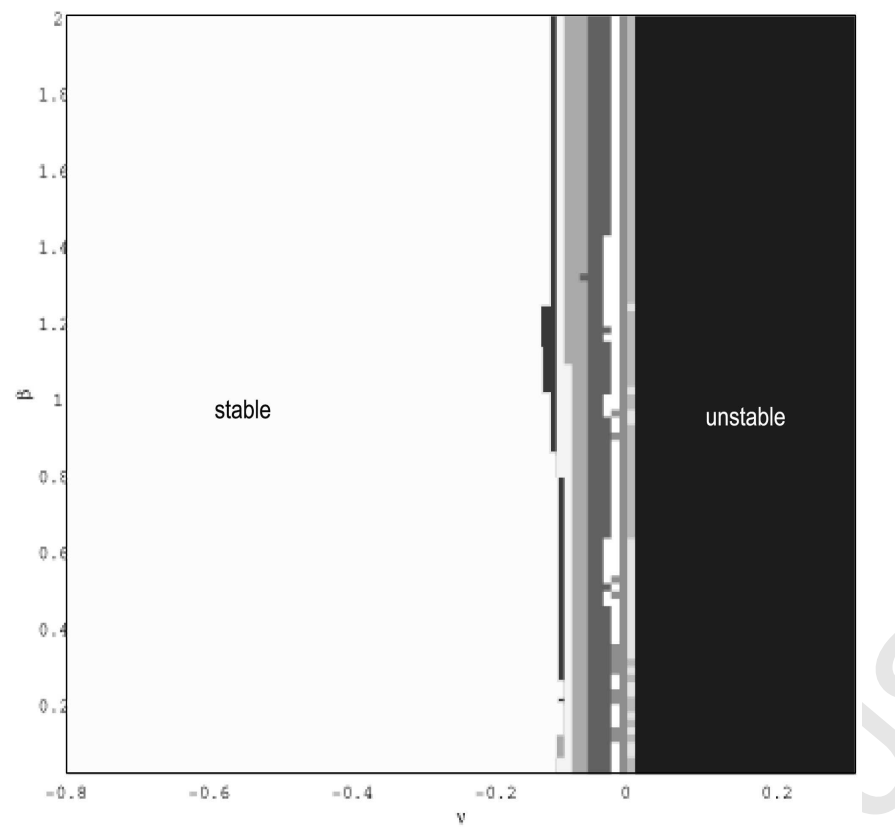

Fig. 9. 2-Parameter bifurcation diagram for $-0.8<\nu<0.3$ and $0<\beta<2$. Other parameters: $\lambda=0.75$, $T=200,20$ pre-iterations. 
Algorithm for the cash-in-advance process.

Initial conditions: $\mathbf{p}(0,1)$ random, $\ell_{i}^{h}(0,1)=-\infty, u_{i}^{h}(0,1)=+\infty$, $\mu^{h}(0,1)=0, M^{h}(0,1)=100$.

For Period $t=1, \ldots, T$ execute Trading Round Rule $\mathbf{T R}(\mathbf{t})$ :

For Market $i=1, \ldots, m$ execute Market Visiting Rule $\mathbf{M V}(\mathbf{t}, \mathbf{i})$ :

For every agent $h \in \mathbf{N}$ :

1. $\tilde{z}_{i}^{h}:=\mathbf{E}_{i}^{h}\left(\mathbf{p}, \tilde{\ell}_{-i}^{h}, \tilde{u}_{-i}^{h}, \mu_{i}^{h}\right)$

$d_{i}^{h}:=\max \left\{0, \tilde{z}_{i}^{h}\right\}, D_{i}:=\sum_{h} d_{i}^{h}$

$s_{i}^{h}:=\min \left\{0, \tilde{z}_{i}^{h}\right\}, S_{i}:=-\sum_{h} s_{i}^{h}$

2. $\hat{z}_{i}^{h}:=\min \left\{\tilde{z}_{i}^{h}, M^{h} / p_{i}\right\}$

3. $\bar{z}_{i}^{h}:=\mathbf{F}_{i}^{h}\left(\hat{z}_{i}^{1}, \ldots, \hat{z}_{i}^{N}\right)$

4. $\left(\ell_{i}^{h}, u_{i}^{h}\right):=\mathbf{G}_{i}^{h}\left(\tilde{z}_{i}^{h}, \bar{z}_{i}^{h}\right)$

5. $\left(\tilde{\ell}_{i}^{h}, \tilde{u}_{i}^{h}\right):=\mathbf{H}_{i}^{h}\left(\ell_{i}^{h}, u_{i}^{h}\right)=\beta \cdot\left(\ell_{i}^{h}, u_{i}^{h}\right)$

6. $R^{h}(t, i):=-p_{i}(t, i) \bar{z}_{i}^{h}(t, i)$

7. $M^{h}(t, i+1):=M^{h}(t, i)+R^{h}(t, i)$

8. $\mu^{h}(t, i+1):=\min \left\{M^{h}(t-1, i+2), \ldots, M^{h}(t-1, m), M^{h}(t, 1), \ldots, M^{h}(t, i+1)\right\}$

9. $p_{i}(t, i+1):=\max \left\{\left(1-r^{-}\right) \cdot p_{i}(t, i), \min \left\{p_{i}(t, i)\left(\frac{D_{i}(t, i)}{S_{i}(t, i)}\right)^{\lambda},\left(1+r^{+}\right) \cdot p_{i}(t, i)\right\}\right\}$

end of market visit

end of period

end of simulation.

Fig. 10. Pseudo code algorithm for the sequential cash-in-advance process. The time-index $(t, i)$ has been suppressed in steps 1-5 for clarity of exposition. Note that there is no price normalization step after price adjustments since there is a positive money stock.

Money balances at the start of every period $(\nu=-0.1)$
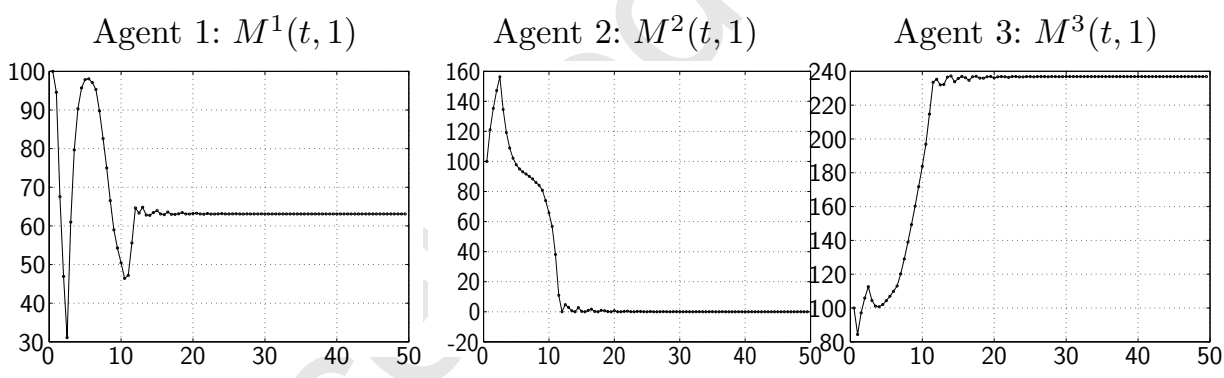

Fig. 11. Model 3. Cash process with end-of-period updating. Parameters: $\nu=-0.1, \lambda=1$. This is an example showing convergence towards a CIA equilibrium. The time series show the individual money balances at the start of every period for 50 consecutive periods $(1 \leq t \leq 50)$. We observe that the transition path towards a cash-in-advance equilibrium takes approximately 20 periods. The equilibrium corresponding to the substitution parameter $\nu=-0.1$ is slightly shifted from the equilibrium values at $\nu=0$. For agent 1 the equilibrium cash balance is therefore slightly above 60 , and for agent 3 it is slightly below $240: M^{1 \star}=62, M^{2 \star}=0$ and $M^{3 \star}=238$. 


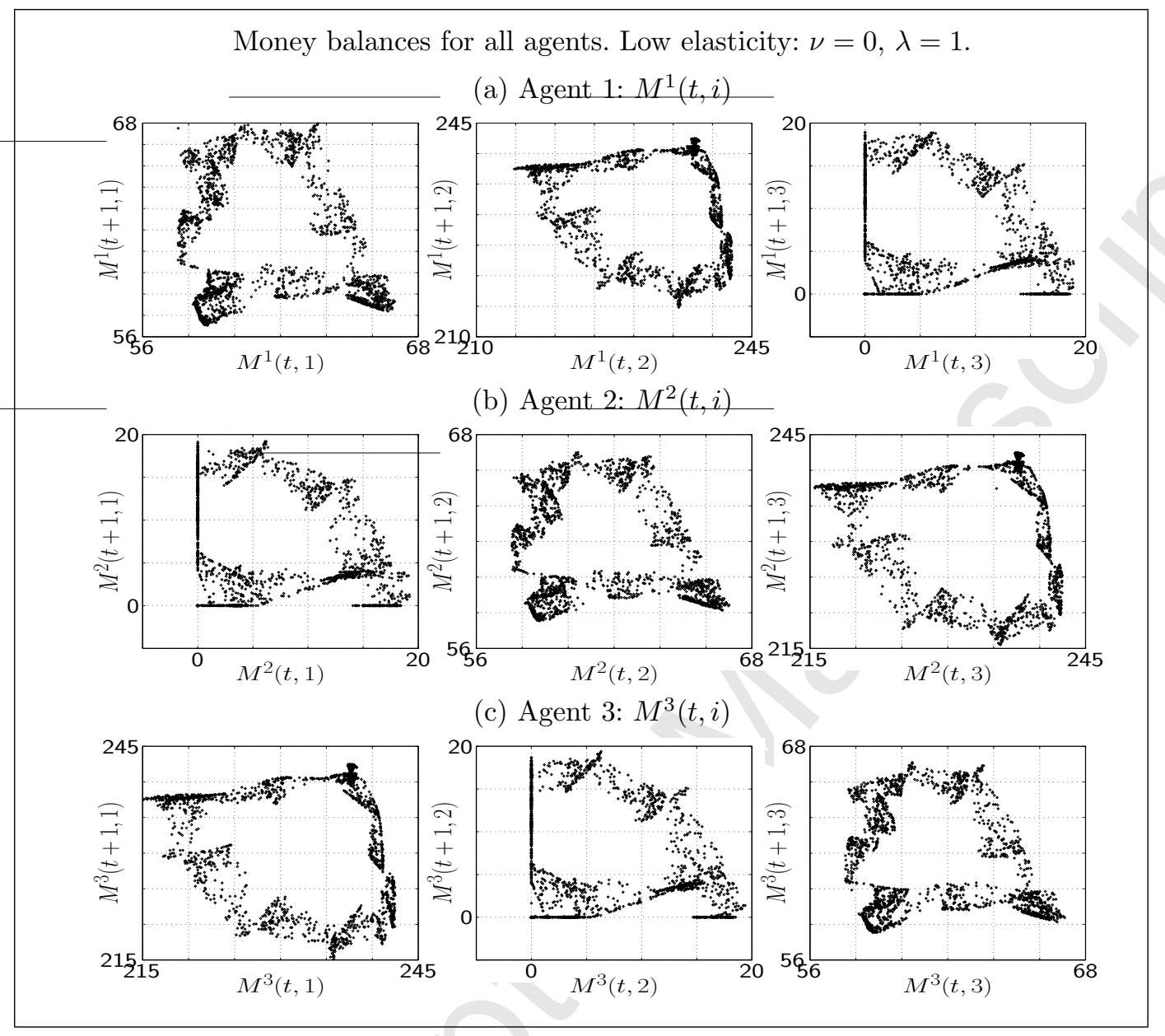

Fig. 12. Model 4. Cash process with sequential updating. Parameters: $\nu=0, \lambda=1$. Phase plots of the individual money holdings: $M^{1}(t, i), M^{2}(t, i)$ and $M^{3}(t, i)$ at the start of every market visit. The first row shows the cash balance for agent 1 at the start of market 1,2 , and 3 . The second row shows the cash balances for agent 2 , and the third for agent 3. Equilibrium values: $\mathbf{p}=(6,6,6)$, $M^{1 \star}=(60,240,0), M^{2 \star}=(0,60,240), M^{3 \star}=(240,0,60)$. Note that the phase plots are centered around the equilibrium values. We observe that the CIA constraint becomes binding on a different market for each agent. 


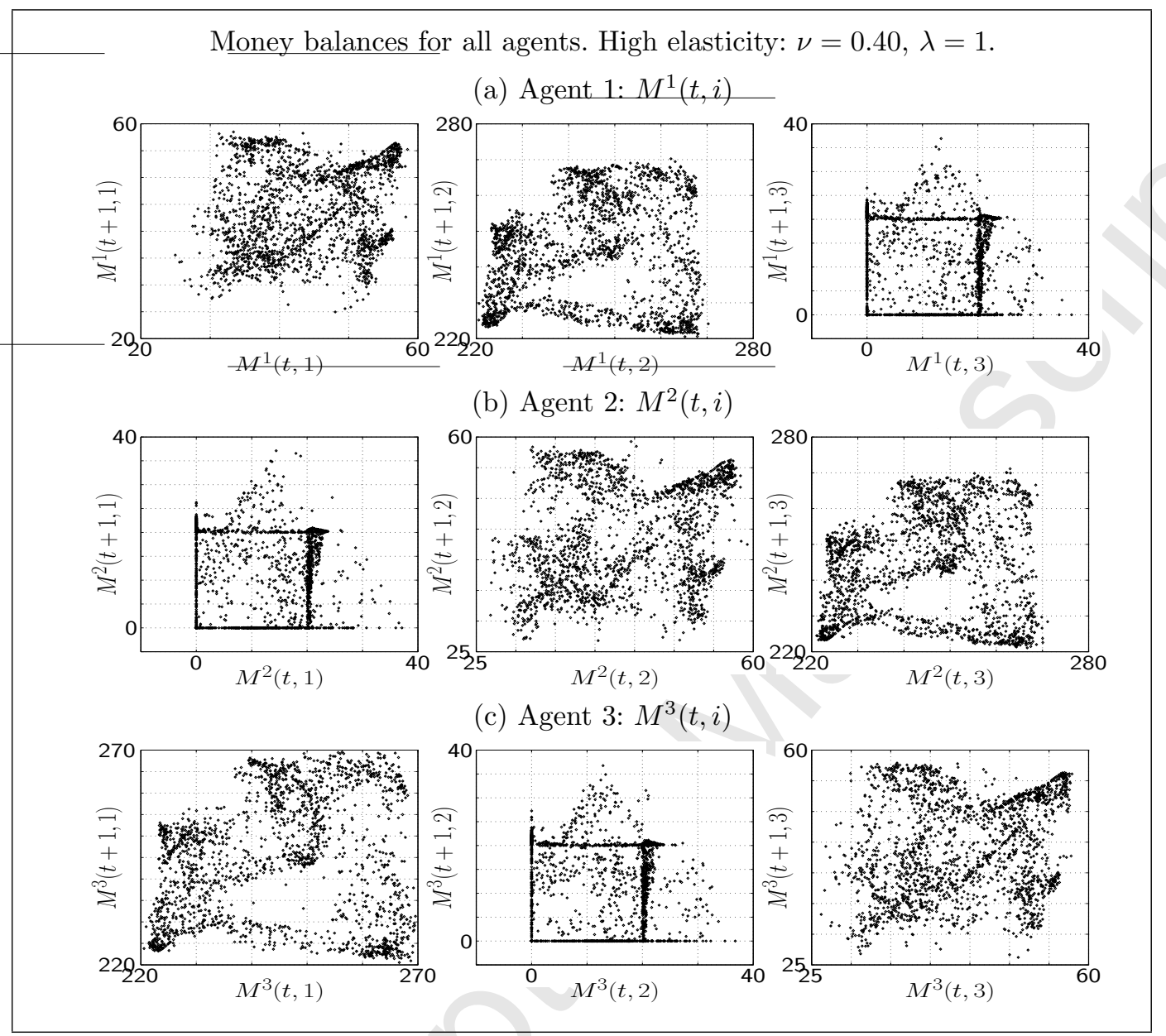

Fig. 13. Model 4. Cash process with sequential updating. Parameters: $\nu=0.40, \lambda=1$. Phase plots of individual money holdings at the start of every market visit: $M^{1}(t, i), M^{2}(t, i)$ and $M^{3}(t, i)$, for $i=1,2,3$. Equilibrium values: $\mathbf{p}=(6,6,6), M^{1 \star}=(40.8,259.2,0), M^{2 \star}=(0,40.8,259.2), M^{3 \star}=(259.2,0,40.8)$. Note that the CIA constraint becomes binding more often due to the higher elasticity of substitution. As a secondary effect there now also exists an upper constraint on the cash positions of the sellers due to the fact that their buyers become cash-constrained more often. 


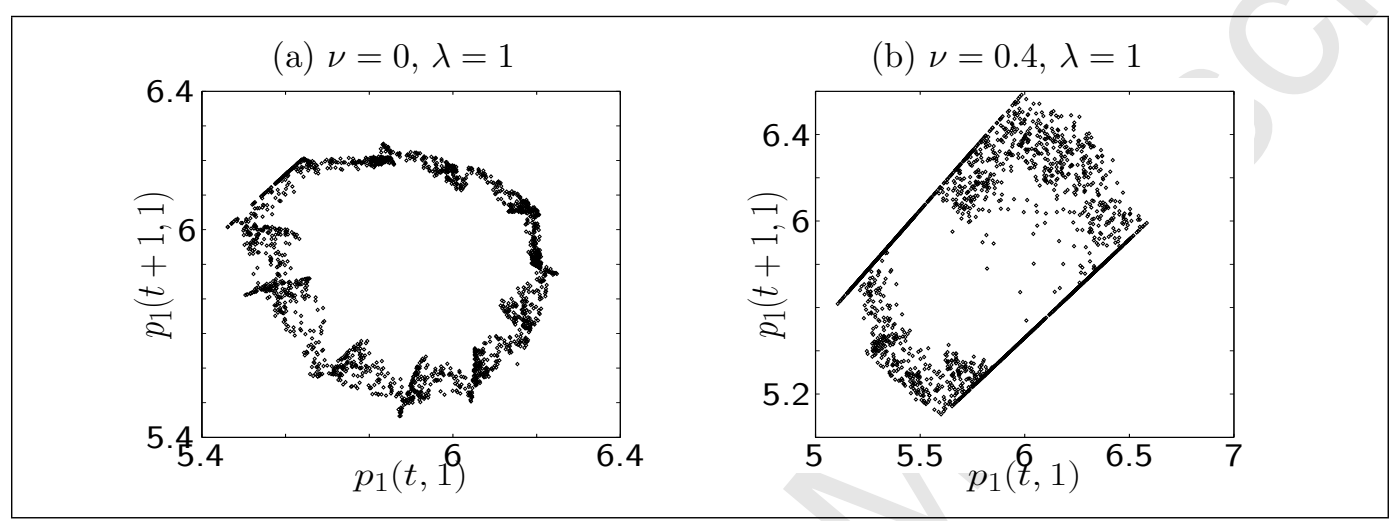

Fig. 14. Model 4. Cash process with sequential updating. Phase plots of the price level $p_{1}(t, 1)$. Parameters: (a) Low elasticity of substitution: $\nu=0, \lambda=1$. (b) High elasticity of substitution: $\nu=0.4$, $\lambda=1$. We observe that for low elasticity of substitution the dynamics remain within the interior of the bounding region. If the elasticity is increased, the price rigidities become binding and the dynamics hit the ceilings and floors. 


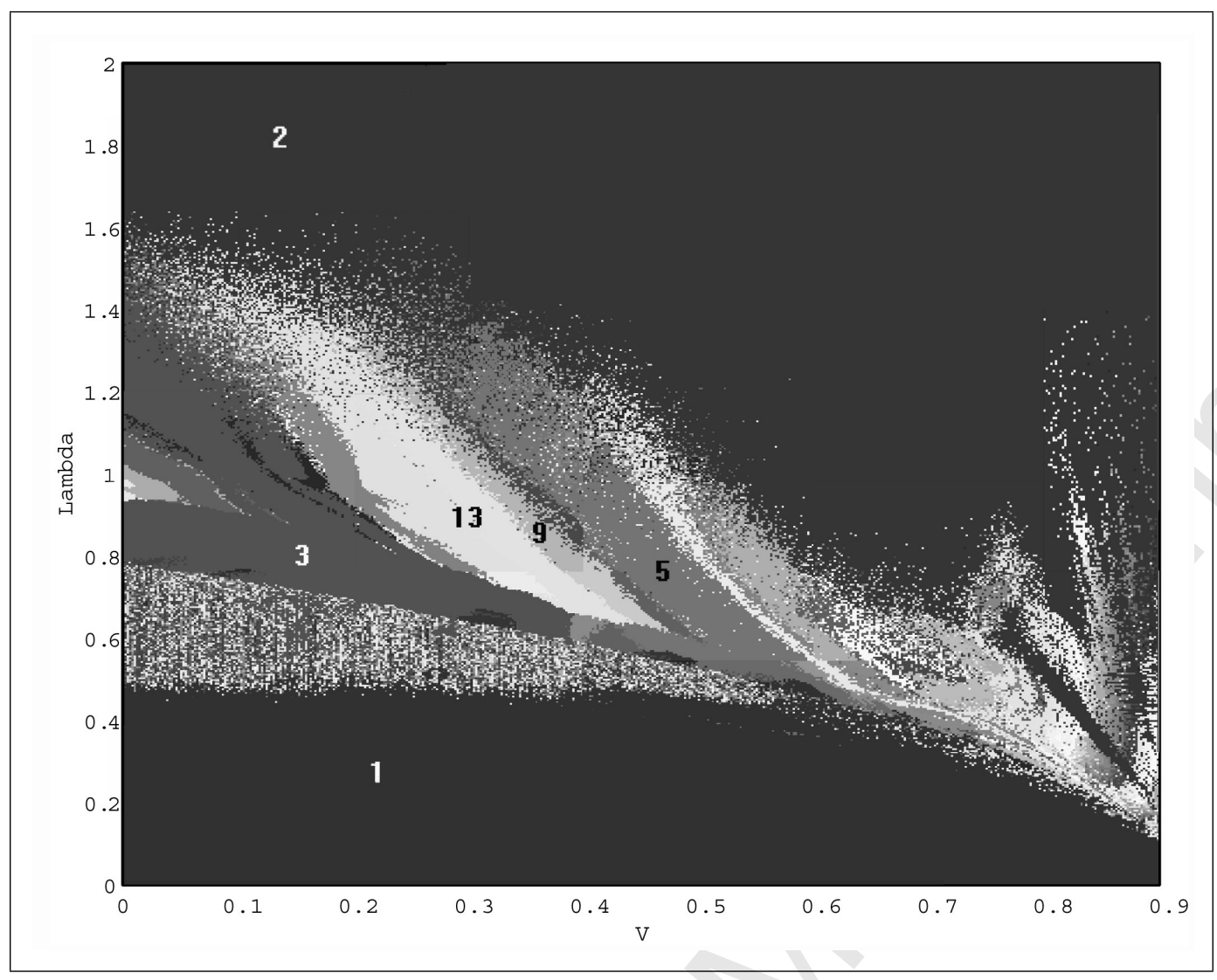

Fig. 15. Model 4. Cash process with sequential updating. 2-parameter bifurcation diagram in the $(\lambda, \nu)$-plane, for $0<\lambda<2,0<\nu<0.9$. 


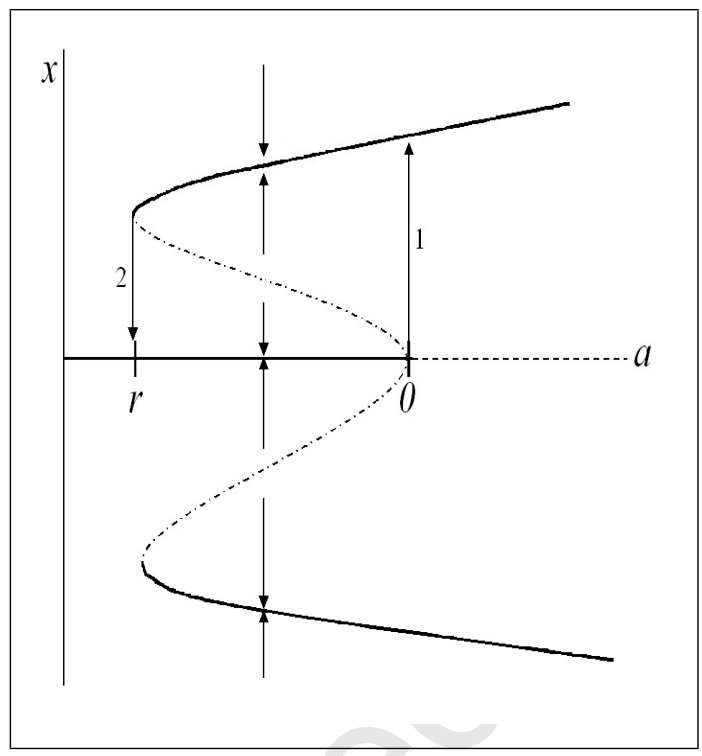

Fig. 16. Hysteresis effect. 